\title{
Solar versus Non-Solar Urine Diversion Dehydration Toilets-Evaluation of Temperatures inside the Vaults of Different UDDT Systems
}

\author{
Constanze Windberg, Ralf Otterpohl \\ Institute of Wastewater Management and Water Protection, Hamburg University of Technology (TUHH), \\ Hamburg, Germany \\ Email: c.windberg@tuhh.de
}

Received 6 May 2016; accepted 26 August 2016; published 29 August 2016

Copyright (C) 2016 by authors and Scientific Research Publishing Inc.

This work is licensed under the Creative Commons Attribution International License (CC BY). http://creativecommons.org/licenses/by/4.0/

(c) (i) Open Access

\section{Abstract}

The Urine Diverting Dehydration Toilet (UDDT) is one of a wide range of technologies Ecological Sanitation (Ecosan) offers. A commonly used type is the so called solar UDDT, constructed with inclined vault doors or panels which are usually made from black iron sheets to increase the temperature inside the vaults and therefore would facilitate dehydration and hygienisation. The study aims to give recommendations on the most appropriate system by comparing solar and non-solar UDDT systems. Existing building standards for UDDTs were reviewed, 133 UDDT sites visited and a comparative temperature study of the temperature inside the vaults of different UDDT systems carried out. The temperature study needed to assess if solar UDDTs would actually succeed in raising the temperature inside the vault. Programmed temperature loggers were placed in the vaults of solar and non-solar UDDTs. The review of building standards showed that the system recommended most is the solar UDDT. The field visits identified a number of problems related to the construction of solar UDDTs. The temperature study showed that solar UDDTs do not necessarily increase the temperature inside the vault significantly and therefore are not speeding up dehydration and pathogen destruction. The study hence concludes that before a solar UDDT system is chosen the climatic conditions have to be assessed carefully. The recommended standard design should be a non-solar UDDT system. It is hoped that the study will facilitate a move towards the construction of non-solar UDDTs.

\section{Keywords}

Ecosan, Sanitation, Solar, UDDT, Temperature, Design 


\section{Introduction}

A successful sanitation system has to be hygienically safe, affordable and user friendly. The neglect of the latter characteristic is often the reason for failed sanitation projects. Hygienic safety and affordability are the main parameters for the development of different designs. The hygienic safety of the overall system has to be guaranteed. The cost has to be within the potential users means. User friendliness will assure satisfied usage. Therefore, there are different designs for each technology available. The different designs should be evaluated at regular intervals to promote the most successful ones and to avoid preventable failures and overspending. This study compares different designs of Urine Diversion Dehydration Toilets (UDDTs)—one common technology of ecological sanitation (ecosan). UDDTs can be designed as single or double vault systems and as solar or non-solar systems.

The double vault system comprises of two chambers or vaults, which contain the faecal material in turn. As soon as one chamber is filled with faecal material it will be closed and the other chamber will be used. If the second chamber is also filled, it will be closed. The dried faecal material of the first chamber will be emptied. This chamber will now be in use and the cycle repeated. Single vault systems use containers to store the faecal material. As soon as one container is filled it is either pushed to the back of the toilet for drying or emptied by a service provider. A new container is placed under the toilet seat. Figure 1(a) and Figure 1(b) show an example of double and single vault UDDT respectively. The shown examples are non-solar UDDT systems. Single and double vault systems can be built with inclined or straight vault doors or panels, which are most commonly made from black iron sheets. It is believed that inclined, black vault doors/panels could serve as so called solar panels. These solar panels would heat up the air inside the vaults to facilitate and speed up dehydration and pathogen destruction (see Figure 1(c)).

After field visits in Uganda 2005, related to a broader research project which focuses on an assessment of hygienic safety of the solid product of UDDTs [1], the common design of solar UDDTs was questioned and the discussed study designed. There were general doubts whether solar panels could achieve the intended temperature rise and whether the supposed benefits of solar UDDTs outweigh their disadvantages. Therefore, this study

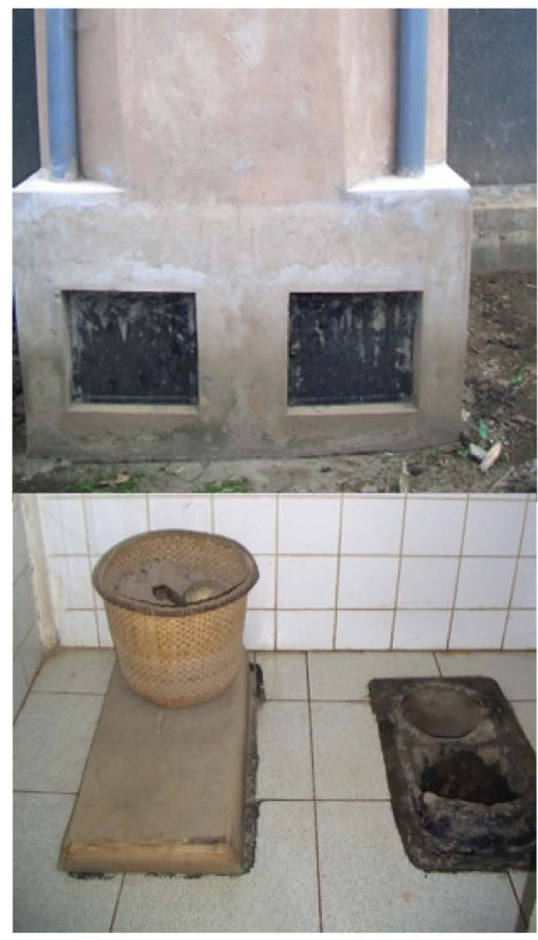

(a)

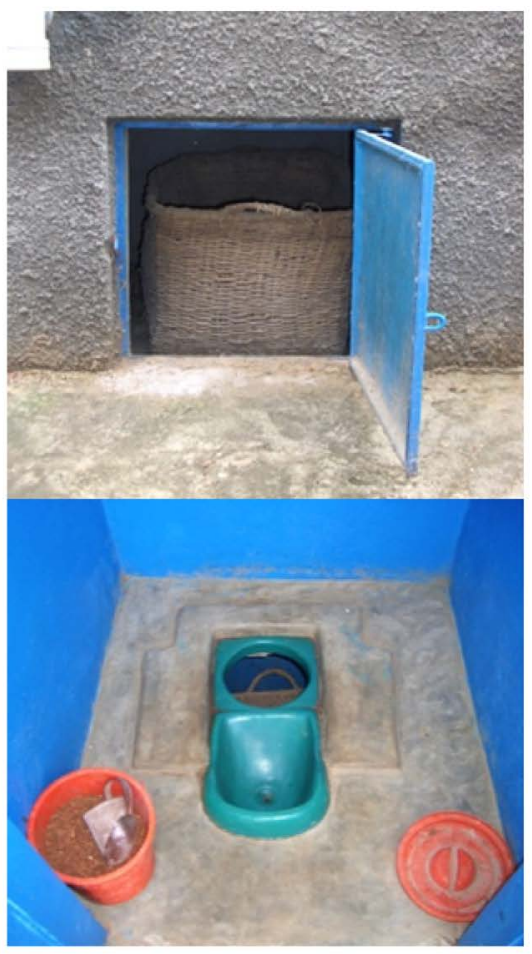

(b)

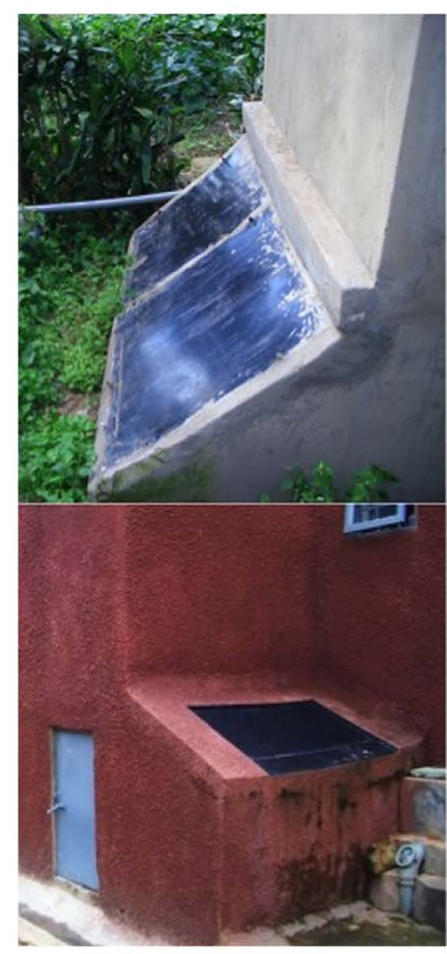

(c)

Figure 1. Different UDDT systems. (a) Non-solar double vault UDDT; (b) Non-solar single vault UDDT; (c) Solar UDDTs (up double vault, below single vault). Photos: Constanze Windberg. 
evaluates and compares the temperatures inside the vaults of solar and non-solar UDDT systems. The main objective of the study is to inform recommendations on the choice of the most appropriate UDDT system. The scientific data presented also strengthen the validity of respective practical experiences with UDDT systems.

\section{Review of the Research Issue}

This study elaborates if solar panels do increase the temperature inside a vault. The data was collected in 2005. It was suggested the data is out-dated and the current practices already adjusted to existing knowledge. However, discussions with practitioners at different platforms and a literature review (see Section 2.1) showed that there is a need for scientifically based data to move away from the construction of solar UDDTs which are still quite common particularly in East Africa.

\subsection{Literature Review of UDDT Construction Manuals and Guidelines}

There are a vast number of UDDT construction manuals and guidelines available [2]-[16]. The majority of reviewed manuals and guidelines explained solar UDDTs as a way to raise the temperature inside the vault, therefore facilitating pathogen die-off (e.g. [2]-[5]). Often, even if not explicitly promoted, the technical drawings or photos show a solar UDDT (e.g. [6]-[8]). Only one publication [9] was found which described the construction of solar UDDTs in a critical way and clearly recommends non-solar UDDTs. The latest UDDT construction guideline [10] published in 2015 does not mention solar UDDTs.

The literature review revealed a shift from advocating solar UDDTs to advocating non-solar UDDTs. One example being Tilley [6] [11]. This publication does not explicitly explain solar and non-solar UDDTs. However, in the revised version of 2014 [11] the technical drawing of a solar UDDT found in the 2008 publication [6] was replaced by a non-solar UDDT. Also GTZ (now GIZ) publications [2] shifted from recommending solar UDDTs to clearly recommending vertical vault doors [9]. Rieck [9] is the only publication, which does state disadvantages of solar UDDTs and doubts the temperature rise. However, no data is provided to strengthen this recommendation. The recommendation was based on experiences from Kenya from 2008 to 2010 [17]. Unfortunately experiences in the field without documented scientific data are often not enough evidence to convince stakeholders. Discussions at conferences and visits at current project sites (see Figure 2) show the shift in academic literature does not yet reflect at practitioners level.
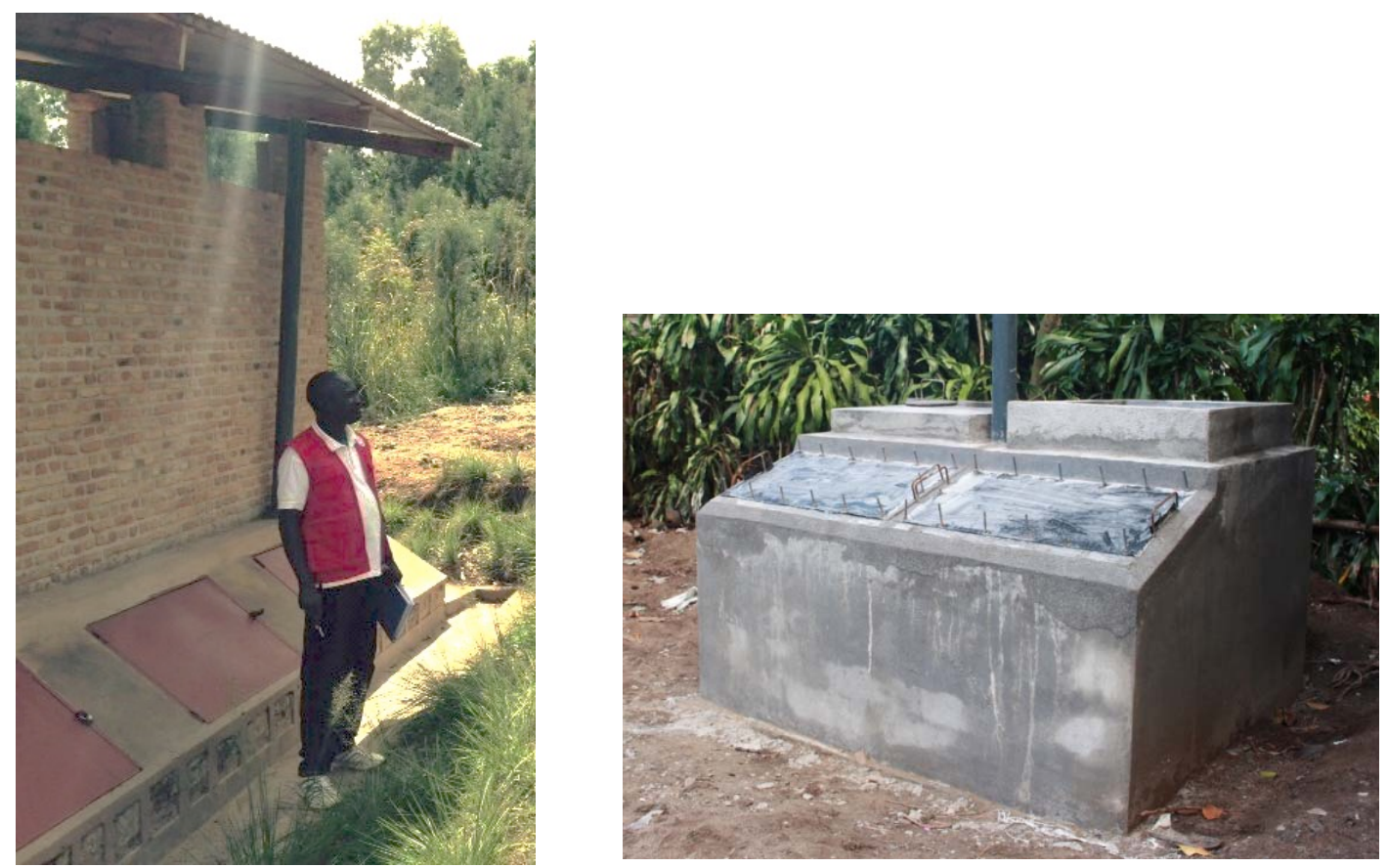

Figure 2. Recently constructed UDDTs. Left: solar UDDT in Burundi constructed 2016. Right: solar UDDT under construction in Madagascar 2014. Photos: left: Chris Brewer, right: Tom Russell. 


\section{Methodology}

The evaluation of temperatures inside the vaults of different UDDT systems was based on findings of field visits of 136 ecosan sites in Uganda in 2005. These field visits aimed to provide an overview of the existing situation in Uganda. Based on the collected data the overall research project including user friendliness, reuse of the produced materials, a hygienic safety study and the temperature study was designed. The temperature study discussed in this paper solely assesses the temperature conditions in solar and non-solar UDDTs. It was considered important to assess real life conditions of toilets under use. Therefore preference was given to a field and not to a laboratory/pilot study. Sites for the temperature study were chosen based on the findings of the initial field visits. The data was collected in different climatic regions in Uganda. However, the results are not specific to these regions in Uganda but can be generalised.

\subsection{Site Selection}

The site selection aimed to cover different climate conditions and different technologies to assure the coverage of a broad range of different conditions. The climate of Uganda cannot be categorized into a single climatic zone. Uganda has three sub-climatic zones differentiated mainly by altitude and rainfall. These three climatic regions are namely the Lake Region, the Northern Savannah, and the Southern Highlands. The chosen study sites covered the three climatic zones, tropical rainforest climate, savannah climate, and warm and temperate highlands climate. The lowest annual average temperature at the chosen sites is $10^{\circ} \mathrm{C}$ in Kabale and the highest annual average temperature is $26.3^{\circ} \mathrm{C}$ in Kitgum (see Table 1 ).

Loggers were placed in 36 UDDTs. These UDDTs were any combination of solar and non-solar systems and single and double vault systems. Plastic containers or woven baskets were used in the single vault UDDTs. Table 1 gives information on the selected sites and the number of placed loggers.

Table 1. Site selection and logger placement.

\begin{tabular}{|c|c|c|c|c|c|c|c|c|c|}
\hline Site & & abale & $\begin{array}{l}\text { Bushara } \\
\text { Island/Lake } \\
\text { Bunyonyi }\end{array}$ & Rwenshama & Kasese & \multicolumn{2}{|c|}{ Kampala } & Nagalama & Kitgum \\
\hline Region & \multicolumn{2}{|c|}{ South-Western } & South-Western & South-Western & Western & \multicolumn{2}{|c|}{ Central } & Central & Northern \\
\hline District & \multicolumn{2}{|c|}{ Kabale } & Kabale & Rukungiri & Kasese & \multicolumn{2}{|c|}{ Kampala } & Mukono & Kitgum \\
\hline $\begin{array}{l}\text { Köppen-Geiger } \\
\text { Climate }^{*}(3)\end{array}$ & \multicolumn{2}{|c|}{ Oceanic Cfb } & $\begin{array}{c}\text { Tropical } \\
\text { Savannah Aw }\end{array}$ & $\begin{array}{c}\text { Tropical } \\
\text { Savannah As }\end{array}$ & $\begin{array}{c}\text { Tropical } \\
\text { Savannah As }\end{array}$ & \multicolumn{2}{|c|}{$\begin{array}{c}\text { Tropical } \\
\text { Rainforest Af }\end{array}$} & $\begin{array}{c}\text { Tropical } \\
\text { Rainforest Af }\end{array}$ & $\begin{array}{c}\text { Tropical } \\
\text { Savannah Aw }\end{array}$ \\
\hline Altitude & 200 & 0 m (2) & 1960 m (4) & 918 m (4) & 1000 m (2) & \multicolumn{2}{|c|}{1190 m (2) } & 1180 m (2) & 760 m (2) \\
\hline $\begin{array}{l}\text { Temperature- } \\
\text { Annual average }\end{array}$ & $\begin{array}{l}17.5^{\circ} \mathrm{C} \\
\text { to } 10^{\circ} \mathrm{C}\end{array}$ & $\begin{array}{l}\text {, can drop } \\
\text { C at night } \\
\text { (1) }\end{array}$ & $21.1^{\circ} \mathrm{C}(3)$ & $23.3^{\circ} \mathrm{C}(3)$ & $19.0^{\circ} \mathrm{C}(3)$ & \multicolumn{2}{|c|}{$21.7^{\circ} \mathrm{C}(3)$} & $21.6^{\circ} \mathrm{C}(3)$ & $24.3^{\circ} \mathrm{C}(3)$ \\
\hline $\begin{array}{l}\text { Average low - } \\
\text { Average } \\
\text { high temperature }\end{array}$ & \multicolumn{2}{|c|}{$\begin{array}{c}10^{\circ} \mathrm{C}-23^{\circ} \mathrm{C} \\
\text { (5) }\end{array}$} & $\begin{array}{c}20.2^{\circ} \mathrm{C}-21.8^{\circ} \mathrm{C} \\
\text { (3) }\end{array}$ & $\begin{array}{c}22.9^{\circ} \mathrm{C}-23.8^{\circ} \mathrm{C} \\
\text { (3) }\end{array}$ & $\begin{array}{c}18.9^{\circ} \mathrm{C}-19.5^{\circ} \mathrm{C} \\
\text { (3) }\end{array}$ & \multicolumn{2}{|c|}{$\begin{array}{c}20.6^{\circ} \mathrm{C}-22.7^{\circ} \mathrm{C} \\
\text { (3) }\end{array}$} & $\begin{array}{c}20.6^{\circ} \mathrm{C}-22.4^{\circ} \mathrm{C} \\
\text { (3) }\end{array}$ & $\begin{array}{c}22.8^{\circ} \mathrm{C}- \\
26.3^{\circ} \mathrm{C}(3)\end{array}$ \\
\hline $\begin{array}{c}\text { Rainfall-Annual } \\
\text { average }\end{array}$ & \multicolumn{2}{|c|}{1018 mm (3) } & 1155 mm (3) & 942 mm (3) & 917 mm (3) & \multicolumn{2}{|c|}{1291 mm (3) } & 1342 mm (3) & 1223 mm (3) \\
\hline $\begin{array}{l}\text { UDDT Technology } \\
\text { (dv = double vault, } \\
\text { sv = single vault) }\end{array}$ & $\begin{array}{l}\text { Solar } \\
\mathrm{dv}\end{array}$ & $\begin{array}{c}\text { Non-solar } \\
\text { dv }\end{array}$ & $\begin{array}{c}\text { Non-solar } \\
\text { dv }\end{array}$ & $\begin{array}{c}\text { Solar } \\
\mathrm{dv}\end{array}$ & $\begin{array}{c}\text { Non-solar } \\
\mathrm{dv}\end{array}$ & $\begin{array}{l}\text { Solar } \\
\mathrm{dv}\end{array}$ & $\begin{array}{c}\text { Non-solar } \\
\text { sv }\end{array}$ & $\begin{array}{l}\text { Solar } \\
\text { sv }\end{array}$ & $\begin{array}{l}\text { Solar } \\
\mathrm{dv}\end{array}$ \\
\hline Number of UDDTs & 6 & 1 & 3 & 7 & 1 & 1 & 5 & 8 & 4 \\
\hline $\begin{array}{l}\text { Total of loggers } \\
\text { placed in toilets }\end{array}$ & & 14 & 3 & 14 & 3 & & 10 & 16 & 8 \\
\hline $\begin{array}{l}\text { Loggers in } \\
\text { Environment }\end{array}$ & & 4 & 1 & 1 & 1 & & 4 & 2 & 2 \\
\hline
\end{tabular}

*Köppen-Geiger Climate Classification: Aw: Tropical wet and dry, savannah climate. As: Tropical wet and dry during period of high sun and long days, savannah climate. Af: Tropical rainforest climate. Cfb: Warm and temperate, oceanic climate. (1) Kampala Fountain Publishers (2005): Uganda Districts Information Handbook, Expanded Edition 2005-2006, Kampala. (2) http://en.wikipedia.org, (Accessed: 03.11.2014). (3) http://en.climate-data.org, (Accessed: 03.11.2014). (4) http://elevationmap.net, (Accessed: 03.11.2014). (5) http://www.weatherbase.com, (Accessed: 03.11.2014). 


\subsection{Data Collection}

To record the data temperature loggers of Maxim Dallas Ltd, MAXIM iButtons, were used. The specific loggers were: High Capacity Temperature Logger DS1922L-F5 and Humidity and Temperature Logger DS1923-F5. These temperature loggers were programmed to take three measurements per day-at $6 \mathrm{am}, 2 \mathrm{pm}$ and $10 \mathrm{pm}$. Two temperature loggers were place inside each selected UDDT. Depending on the UDDT system the loggers were placed either inside the closed vault or inside the container, which was filled, and therefore not in use. One temperature logger was placed on top of the solid material and one in the middle of the pile. An additional temperature logger was placed outside the immediate vicinity of the toilet to record the temperature of the surrounding environment. Figure 3 illustrates the basic research set up.

In order to assure the longest measurement process possible only recently closed vaults or containers were selected. Shortly before the scheduled emptying, after assuring the maximum storage time of the material possible in the closed vaults/containers, the temperature loggers were collected, read out and the data transferred to an Excel sheet. For logistical reasons some temperature loggers had to be removed after a shorter period. The period of data collection varied between 118 and 364 days.

To assess the variance of point measurements inside the same heap, two toilets received two temperature loggers inside the heap. Analysing the data showed that the difference in temperature at different locations inside the heap is negligible. It therefore was considered justified to only place one temperature logger in each heap. Since financial constraints only allowed the purchase of a limited number of temperature loggers, placing only one logger inside the heap of each study UDDT permitted a larger number of project sites.

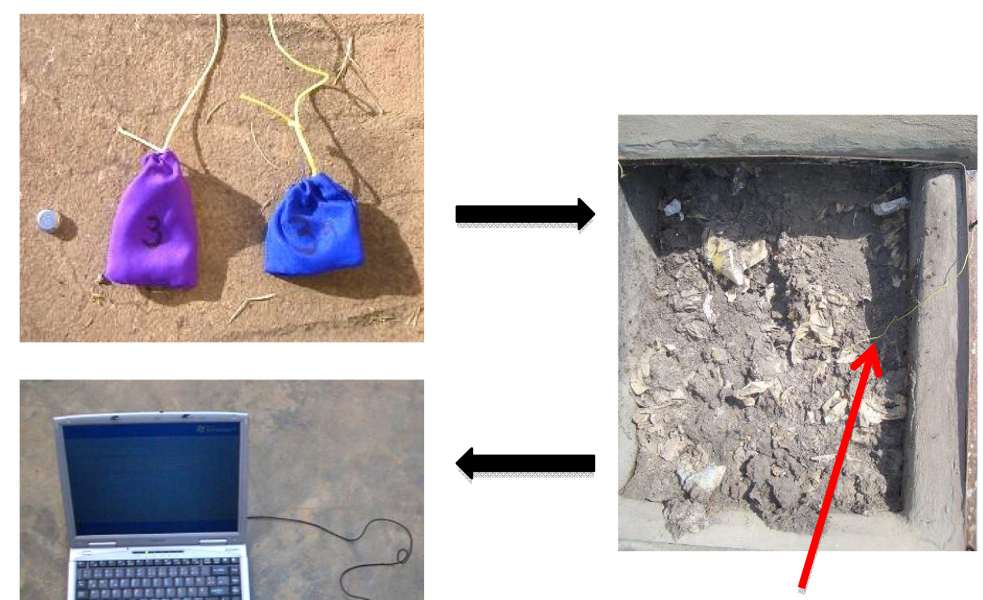

Visible string of temperature logger placed inside the heap

Figure 3. Experimental set up for temperature study, from left to right: Temperature logger, pink bag containing temperature logger to be placed on top of heap, blue bag containing temperature logger to be placed inside heap; Yellow string of blue bag placed inside the heap; Computer, temperature logger, data reading device. Photos: Constanze Windberg.

\section{Results and Discussion}

In this section the results of the field visits, focusing on the distribution of different technologies, will be discussed briefly. The discussion of the temperature study will be comprehensive. Each site is evaluated separately first to then provide a comparison.

\subsection{Extract of Results of Field Visits in Uganda 2005}

In 2005133 ecosan sites in Uganda, that is, sites with resource oriented sanitation systems, were visited and evaluated. Several parameters like technology, cleanliness, smell, number of users, urine collection system, designs for washers and wipers, public, private, subsidies, usage of containers, and hand washing facilities were reviewed. The findings and methodology of the field visits, including the inspection protocol, are discussed in 
detail in a separate paper. This section will focus solely on the findings relevant to the choice of technology. Figure 4 illustrates the proportional distribution of the different technologies at the visited sites.

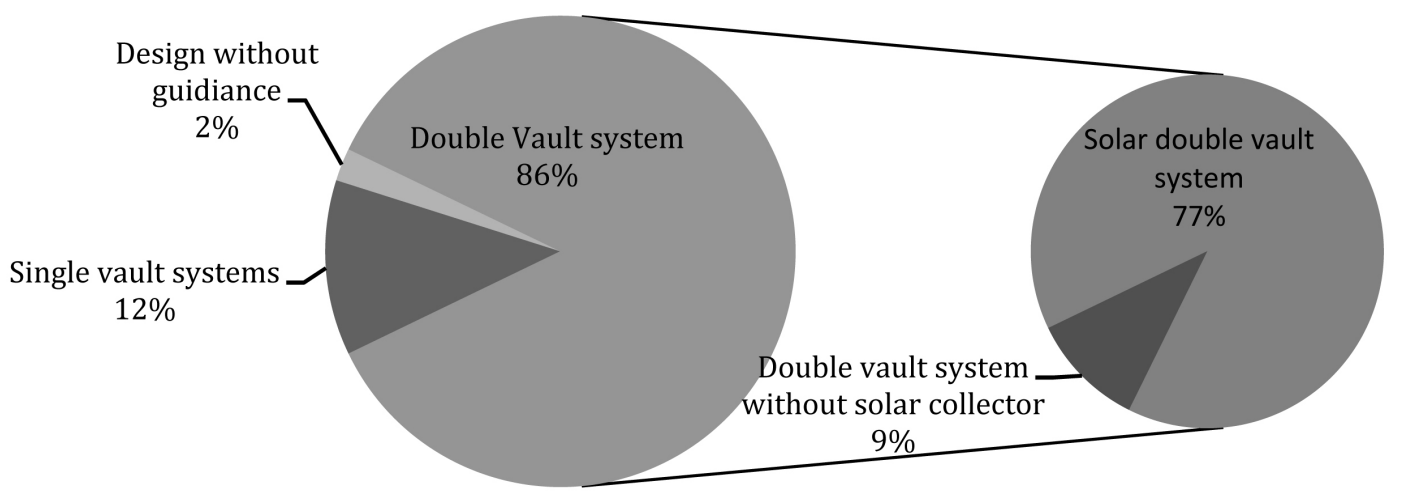

Figure 4. Ecosan technologies at visited sites.

With the exception of three (2\%) sites, all visited toilets were Urine Diversion Dehydration Toilets. Double and single vault systems were installed. 86\% (114) of the visited toilets were double vault systems and 12\% (16) single vault systems. The three sites with systems other than UDDT were designed for reuse of urine and/or faeces without following any guidelines. Even though the systems are reuse orientated they can't be labelled "ecosan" since there is no safe sanitization of the faecal material guaranteed.

Only $11 \%$ of the double vault systems were constructed without solar heating. 89\% (102) of the 114 double vault systems and $50 \%$ (8) of the single vault systems were constructed with iron sheets, mostly black, to absorb the heat of the sun and increase the temperature inside the vault. These systems are commonly referred to as solar double/single vault systems. Therefore out of 133 visited UDDTs 110 (83\%) were solar heated. The solar heated UDDT was definitely the preferred design.

The visited solar UDDTs were designed in various ways using different materials. Four major problem areas were identified:

1) Because of the tilted chambers, building so called solar heated UDDTs complicates the construction and increases the cost considerably.

2) Inclined vault doors are more exposed to direct rain and therefore corrode much faster depending on the used quality of the iron sheets (see Figure 5).
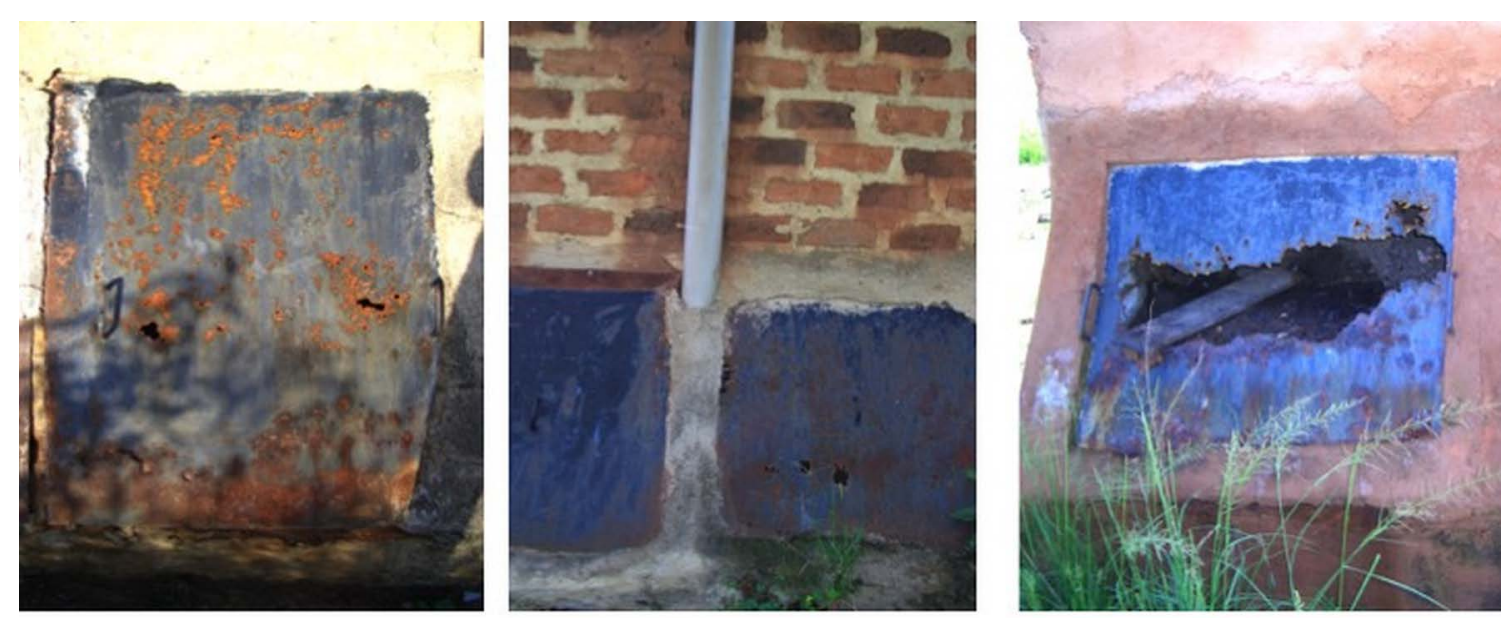

Figure 5. Corroded iron sheets of solar UDDTs. Photos: Constanze Windberg.

3) In contrast to vertical vault doors, inclined vault doors have to be watertight due to their exposure to direct rainfall. This cannot always be guaranteed (see Figure 6). 


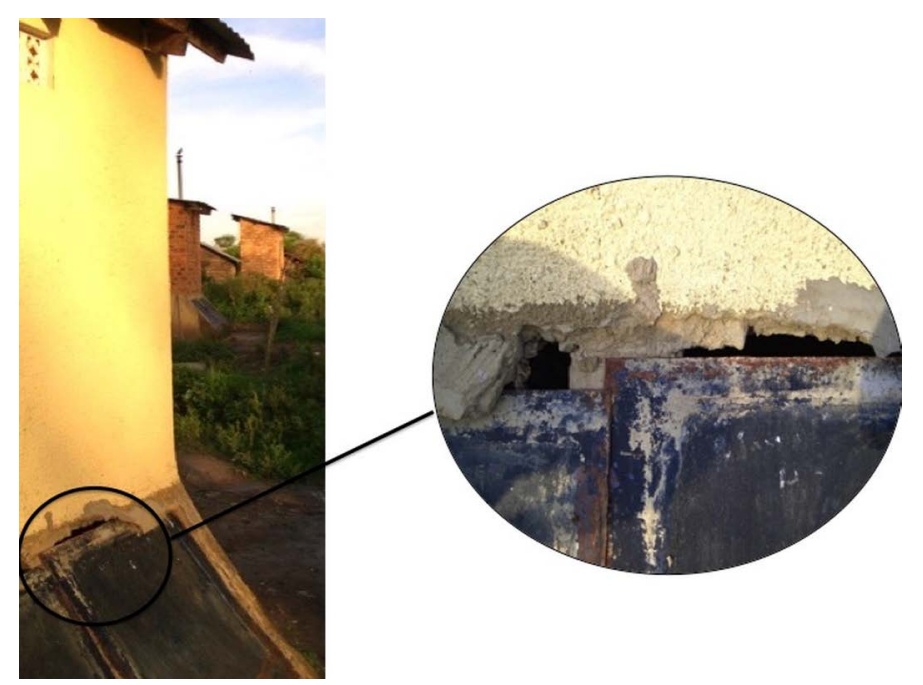

Figure 6. Water tightness of vault compromised by poor quality of mortar. Photo: Constanze Windberg.

4) The solar UDDTs are not necessarily oriented according to the sun's path but more likely for the comfort of the user (see Figure 7).

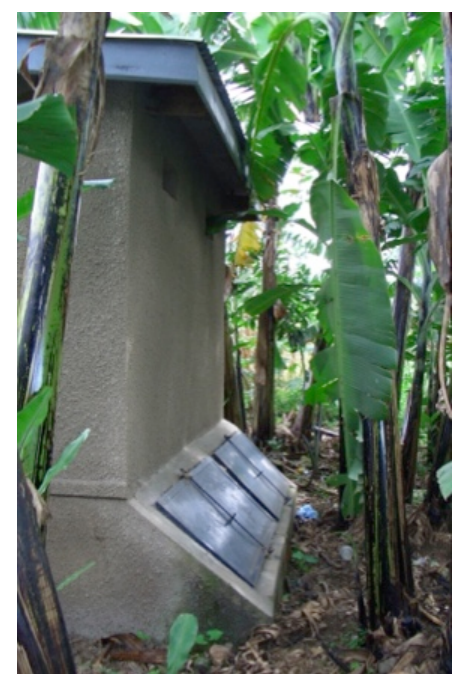

Figure 7. Solar UDDT located in permanent shade. Photo: Constanze Windberg.

\subsection{Results and Discussion of Study on Temperature inside Vaults}

The temperature loggers were collected as soon as the respective vault/basket/container was about to be emptied. During collection of the temperature loggers it became apparent that of the 83 temperature loggers placed in 36 UDDTs and in the environment 21 temperature loggers were missing at the time of sampling. Therefore not all UDDTs studied could be evaluated. If only one of the loggers placed inside the vault was missing the respective data is still discussed. If the logger placed in the environment was missing it was not possible to discuss the respective UDDTs, due to the lack of reference data. Table 2 provides an overview of missing data loggers and evaluated UDDTs. In Boyonyi/Bushara Island and Kasese the temperature loggers placed in the environment were missing. Therefore these sites are not included in the discussion. Despite the number of non-evaluated sites the evaluation still covers four different climate regions. The initial study ratio of 26 solar UDDTs to 10 nonsolar UDDTs changed to 24 solar to 4 non-solar evaluated UDDTs. Of the 24 evaluated solar UDDTs 8 were single vault systems. Of 36 initial sites 28 could be evaluated. 
Table 2. Overview of evaluated UDDTs.

\begin{tabular}{|c|c|c|c|c|c|c|c|}
\hline Site & \multicolumn{2}{|c|}{ Kabale } & Kitgum & \multicolumn{2}{|c|}{ Kampala } & Nagalama & Rwenshama \\
\hline $\begin{array}{l}\text { Total loggers } \\
\text { lost, or no data }\end{array}$ & \multicolumn{2}{|c|}{4} & 3 & \multicolumn{2}{|c|}{5} & 2 & 5 \\
\hline $\begin{array}{l}\text { Environment } \\
\text { loggers lost }\end{array}$ & \multicolumn{2}{|c|}{1} & & \multicolumn{2}{|c|}{1} & 2 & \\
\hline Technology & $\begin{array}{c}\text { Solar } \\
\text { double } \\
\text { vault } \\
\text { UDDT }\end{array}$ & $\begin{array}{c}\text { Non solar } \\
\text { single } \\
\text { vault } \\
\text { UDDT }\end{array}$ & $\begin{array}{c}\text { Solar } \\
\text { double vault } \\
\text { UDDT }\end{array}$ & $\begin{array}{c}\text { Solar } \\
\text { double } \\
\text { vault } \\
\text { UDDT }\end{array}$ & $\begin{array}{l}\text { Non solar } \\
\text { single vault } \\
\text { UDDT }\end{array}$ & $\begin{array}{c}\text { Solar single } \\
\text { vault UDDT }\end{array}$ & $\begin{array}{l}\text { Solar double } \\
\text { vault UDDT }\end{array}$ \\
\hline $\begin{array}{l}\text { Final number of } \\
\text { evaluated UDDTs }\end{array}$ & 6 & 1 & 4 & 1 & 3 & 8 & 5 \\
\hline $\begin{array}{l}\text { Period of data } \\
\text { collection in days }\end{array}$ & \multicolumn{2}{|c|}{$170-280$} & 118 - 364 & \multicolumn{2}{|c|}{$220-310$} & $207-246$ & $150-364$ \\
\hline
\end{tabular}

To illustrate the temperature tendencies over the study period graphically it was decided to present the mean values of the measurements in 10-day intervals. In addition to the graphs, a comparison of minimum and maximum measurements inside the vault with the minimum and maximum measurements in the environment is presented. Furthermore, the mean temperature values inside and outside the heap and in the environment over the whole study period are compared. The following sections evaluate each site separate.

\subsubsection{Kabale}

Kabale is located in South Western Uganda at $2000 \mathrm{~m}$ above sea level. The climatic region is oceanic with warm and temperate climate. The annual average temperature is between $10^{\circ} \mathrm{C}$ and $23^{\circ} \mathrm{C}$ (see Table 1). Relative humidity is between $90 \%$ and $100 \%$ in the morning and decreases to between $42 \%$ and $75 \%$ in the afternoon [18]. The average annual rainfall amounts to $1018 \mathrm{~mm}$ (see Table 1). With the exception of KAB 3 all evaluated UDDTs are solar UDDTs (see Figure 8).
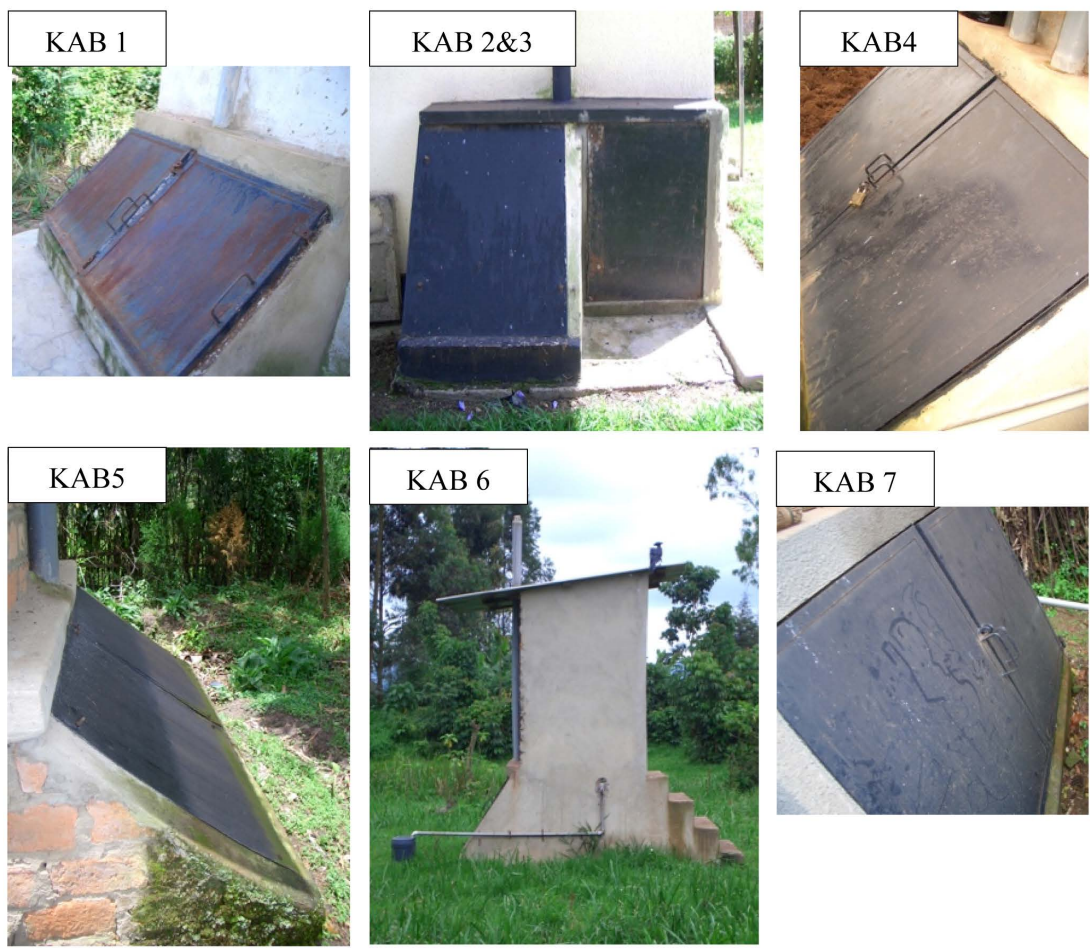

Figure 8. Project sites for evaluation of temperature inside the vault in Kabale, KAB1KAB7. Photos: Constanze Windberg. 
Of the 18 data loggers placed in seven toilets and the surroundings four data loggers were missing. Since one missing data logger was placed in the environment, it was not possible to fully evaluate two toilets, KAB $2 \& 3$. However, these sites are still included in the discussion since KAB 2 is a single vault solar UDDT immediately neighbouring KAB 3 which is a non-solar UDDT system (see Figure 8). Therefore just comparing the inside temperature already allows some conclusions regarding the functionality of solar and non-solar technologies. The results of the readings of the temperature loggers in Kabaleare illustrated in the graphs of Figure 9.
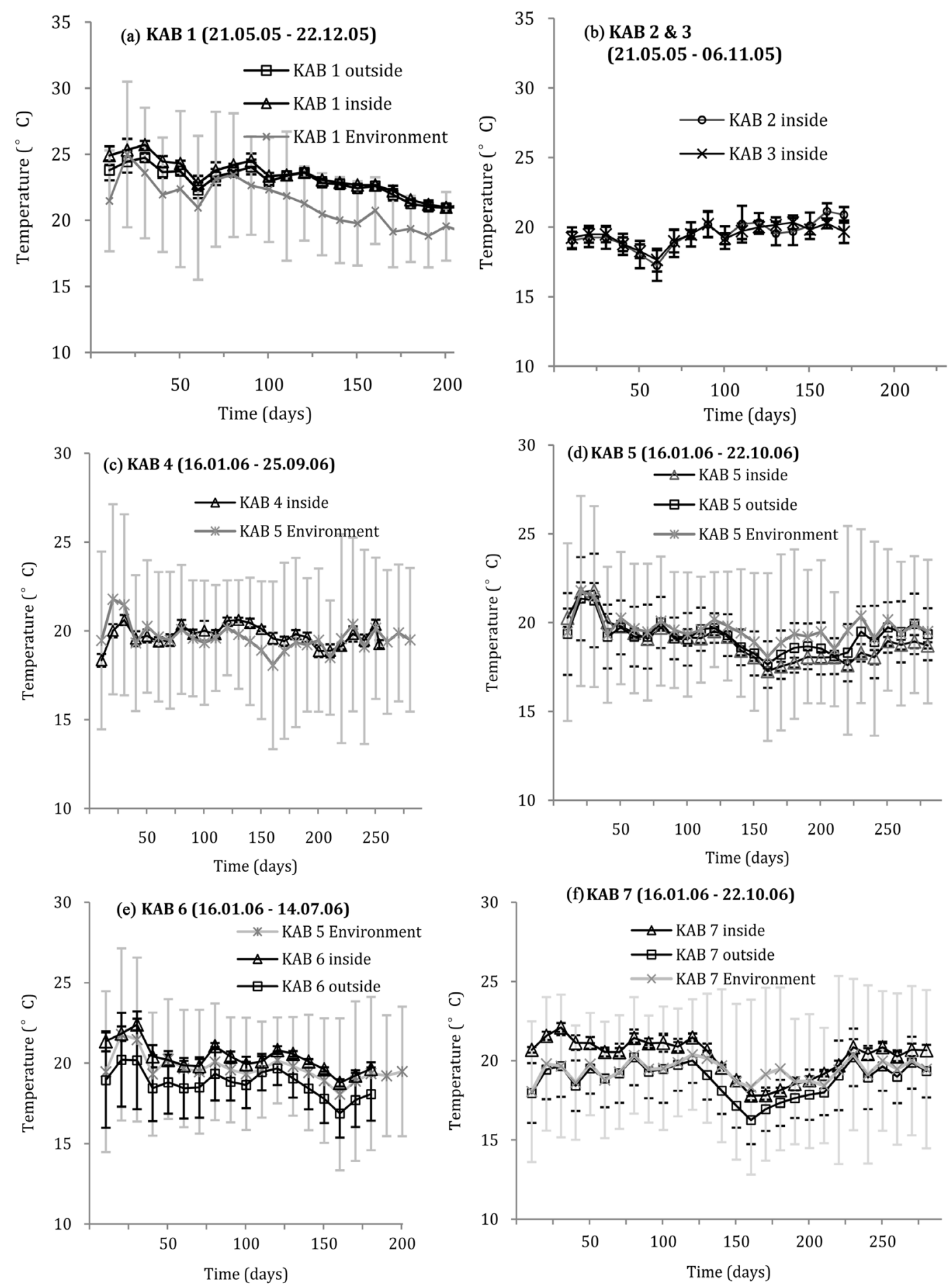

Figure 9. Results of temperature measurements inside the vaults and in the environment in Kabale area, sites KAB 1-KAB 7. 
The study period of KAB 1 is 21.05.2005 to 22.12.2005, 216 days, whereas KAB $2 \& 3$ was emptied earlier at 06.11.2005 after 170 days. It can be seen that the trend of the temperature is similar at both sites. Hereby considering $\mathrm{KAB} 2 \& 3$ as one site. Around day 60 there is a temperature low at both sites and around day 9 the temperature reached a maximum again at both sites.

Even though KAB 2 is a solar and KAB 3 is a non-solar UDDTs the temperatures inside the vaults are the same. The toilets are located in the shade. Therefore the construction of a solar panel does not have any effect on the temperature inside the heap, as shown by the measurements. At KAB $2 \& 3$ three loggers were missing-two placed outside the heap and one placed in the environment. Therefore a comparison between the temperature outside and inside the heap and a comparison with the temperature in the environment is not possible.

The measurements at KAB 4 were taken from 16.01.2006 until 25.09.2006 for 253 days, at KAB 6 from 16.01.2006 until 14.07.2006 for 180 days and measurements at KAB 5 and 7 were taken from 16.01.2006 until 22.10.2006 for 280 days. The generally lower temperatures of KAB 4, 5, 6, and 7 compared to KAB 1, 2 \& 3 might be due to the different monitoring period. Since KAB 4, 5, and 6 are neighbouring sites, one environment logger was used for all three sites. The logger placed outside the heap of KAB 4 disappeared.

The graphs show that at KAB 1 the temperatures inside and outside the heap are above the environment temperature. With the inside and outside temperature being very similar. The temperature inside the heap at KAB 4 is similar or slightly above the environment temperature. At KAB 5 the temperatures inside the vault are similar or slightly below the environment temperature, whereas at KAB 6 the temperature inside the heap is above the environment and the temperature outside the heap is below the environment temperature. At KAB 7 the graph of the temperature inside the heap is mainly above the environment temperature and the graph of the temperature outside the heap similar or below the environment temperature. The visuals of the graphs are reflected in the following tables. Table 3 illustrates minimum and maximum temperature measurements for KAB 1-7 and minimum and maximum temperature measurements for Environment KAB 1, Environment KAB 5, and Environment $\mathrm{KAB} 7$.

Table 3. Minimum and maximum temperatures inside and outside the heap for KAB 1-7, minimum and maximum temperatures Environment KAB 1, Environment KAB 5, Environment KAB 7.

\begin{tabular}{|c|c|c|c|c|}
\hline \multirow{2}{*}{ Site } & \multicolumn{2}{|c|}{ Temperature inside heap } & \multicolumn{2}{|c|}{ Temperature outside heap } \\
\hline & Min & Max & Min & Max \\
\hline KAB 1 & 20.67 & 26.17 & 20.67 & 25.17 \\
\hline Environment KAB1 & & & \multicolumn{2}{|c|}{34.65} \\
\hline KAB 2 & 15.16 & 22.17 & - & - \\
\hline KAB 3 & 16.20 & 21.21 & - & - \\
\hline \multicolumn{5}{|c|}{ No environment measurement for KAB $2 \& 3$ available } \\
\hline KAB 4 & 17.65 & 21.15 & - & - \\
\hline KAB 5 & 17.15 & 22.66 & 15.16 & 25.67 \\
\hline KAB 6 & 18.65 & 23.15 & 13.65 & 25.67 \\
\hline Environment KAB 5 & \multicolumn{2}{|c|}{ Min } & \multicolumn{2}{|c|}{ Max } \\
\hline -Period of 253d (KAB 4) & \multicolumn{2}{|c|}{9.58} & \multicolumn{2}{|c|}{31.10} \\
\hline -Period of 280d (KAB 5) & \multicolumn{2}{|c|}{9.58} & \multicolumn{2}{|c|}{31.10} \\
\hline -Period of 180d (KAB 6) & \multicolumn{2}{|c|}{10.08} & \multicolumn{2}{|c|}{31.01} \\
\hline KAB 7 & 17.15 & 22.66 & 13.65 & 23.67 \\
\hline \multirow[t]{2}{*}{ Environment KAB 7} & \multicolumn{2}{|c|}{ Min } & \multicolumn{2}{|c|}{ Max } \\
\hline & \multicolumn{2}{|c|}{10.15} & \multicolumn{2}{|c|}{28.18} \\
\hline
\end{tabular}


Figure 9 and Table 3 show that the temperature inside the heap at KAB 1 is considerably higher than at KAB $2 \& 3$ with respective maximum temperatures of $26.17^{\circ} \mathrm{C}$ and $22.17^{\circ} \mathrm{C} \& 21.21^{\circ} \mathrm{C}$ and respective average temperatures (see Table 4) of $23.21^{\circ} \mathrm{C}$ and $19.48^{\circ} \mathrm{C} \& 19.45^{\circ} \mathrm{C}$. The different locations and the positioning of the vaults at the respective sites can explain this.

At all sites the minimum temperatures inside and outside the heap are above the minimum environment temperature, with the difference ranging between $3.5^{\circ} \mathrm{C}$ and $8.57^{\circ} \mathrm{C}$. However, the maximum temperatures inside and outside the heap are always below the maximum temperatures in the environment. With the temperature difference ranging between $4.51^{\circ} \mathrm{C}$ and $9.95^{\circ} \mathrm{C}$. Table 4 shows the average temperatures of the inside and the outside of the heap and the environment and indicates the trend lower or higher than the environment temperature with respective arrows.

Table 4. Average temperature inside and outside the heap of KAB 1-7 and average temperature in the respective environment.

\begin{tabular}{cccccc}
\hline & & Inside & & Average & \multicolumn{2}{c}{ Outside } \\
\cline { 2 - 5 } Site & & Average & Environment & Average & $\uparrow$ \\
KAB 1 & $\uparrow$ & 23.21 & 21.22 & 22.82 & - \\
KAB 2 & - & 19.48 & - & - & - \\
KAB 3 & - & 19.45 & - & - & - \\
KAB 4 & $=\uparrow$ & 19.75 & 19.65 & 19.21 & $\downarrow$ \\
KAB 5 & $\downarrow$ & 18.95 & 19.64 & 18.75 & $\downarrow$ \\
KAB 6 & $\uparrow$ & 20.34 & 19.70 & 18.80 & $=/ \downarrow$ \\
KAB 7 & $\uparrow$ & 20.23 & 19.39 & & $\downarrow$ \\
\hline
\end{tabular}

$\uparrow$ : Temperature higher than environment. $\downarrow$ : Temperature lower than environment.

$\mathrm{KAB}$ 1, 5, 6 \& 7 had temperature loggers inside and outside the heap. In KAB 1, 6 \& 7 the average temperature inside the heap is higher than the average temperature outside the heap and the average environment temperature. For KAB 5 the outside and the environment temperatures are higher than the inside temperature for the last 125 days of the 280 days study period. For the rest of the study period the inside and outside temperature are either the same or the inside temperature is slightly higher. It can be seen that the mean temperatures inside the heap are mostly higher than the environmental temperatures, except for KAB 5. However, the temperature difference between the temperature inside the heap and environment temperature only ranges between $0.10^{\circ} \mathrm{C}$ and $1.99^{\circ} \mathrm{C}$. Whereas the temperature outside of the heap is mostly lower or the same than the average environment temperature, the difference ranging between $0.43^{\circ} \mathrm{C}$ and $0.95^{\circ} \mathrm{C}$. Only KAB 1 has a slightly higher average temperature outside the heap of $1.6^{\circ} \mathrm{C}$ compared to the temperature in the environment. The average temperatures inside the heap being higher than the average temperatures outside the heap and in the environment could be explained by higher daily temperature differences in the environment and outside the heap compared to the better "insulated" inside of the heap.

\subsubsection{Kitgum}

Kitgum is located in Northern Uganda at $760 \mathrm{~m}$ above sea level. The climatic region is tropical wet and dry savannah climate. The annual average temperature is between $22.8^{\circ} \mathrm{C}$ to $26.3^{\circ} \mathrm{C}$ (see Table 1 ). The average annual relative humidity is $61.6 \%$ [19]. The average annual rainfall amounts to $1.223 \mathrm{~mm}$ (see Table 1). All evaluated UDDTs are double vault solar UDDTs. Figure 10 shows the evaluated UDDTs in Kitgum.

Of the ten temperature loggers placed, three went missing. These were the loggers placed outside of the heap at three sites. Only at KIT4 the loggers placed inside and outside the heap were available at the time of emptying. However, unfortunately KIT 4 was already emptied after a period of 118 days. For the Kitgum sites it is therefore only possible to compare the temperature outside the heap with the environment. Two loggers were placed in the environment. The data readings are very similar. Therefore the environment logger at KIT1 will be used for the evaluation of KIT 1-4. Figure 11 illustrates the results of the readings of the temperature loggers in Kabale. 

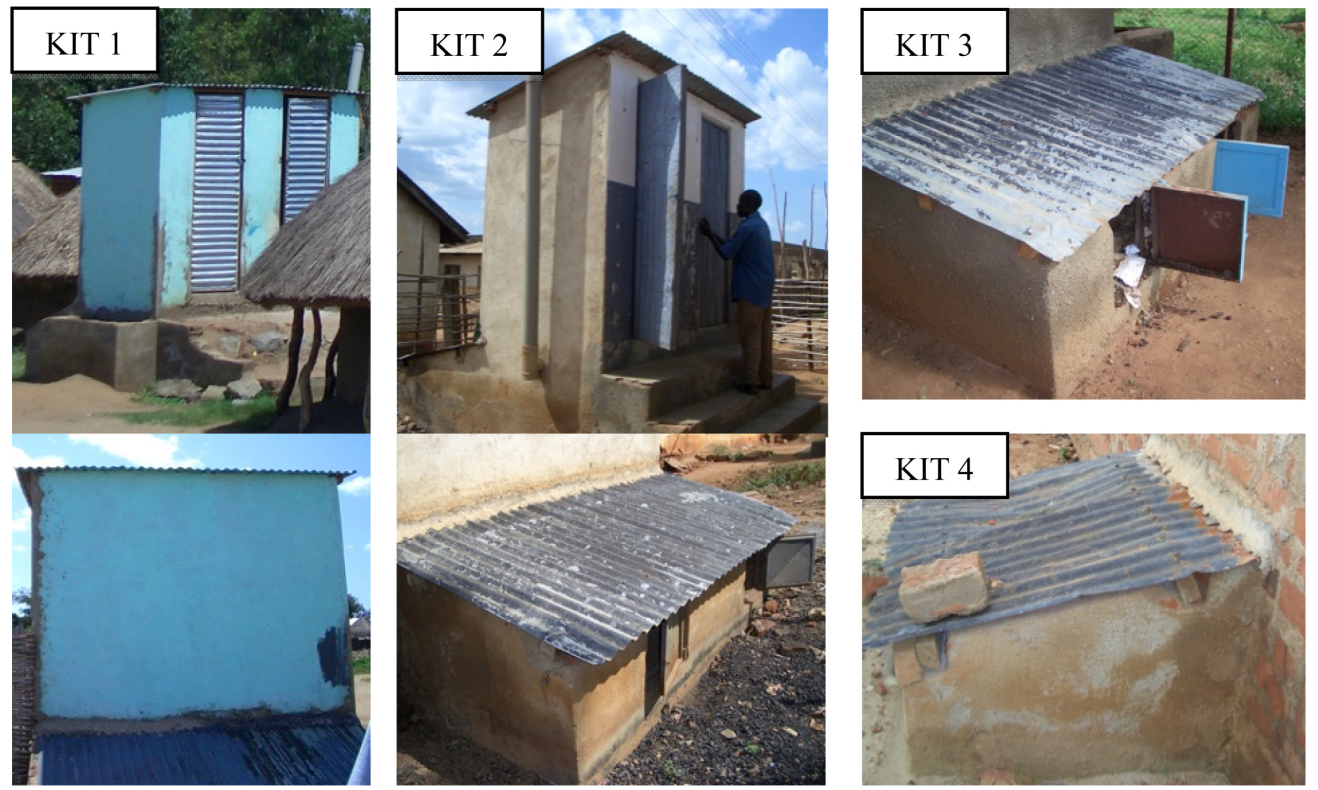

Figure 10. Project sites for evaluation of temperature inside the vault in Kitgum, KIT 1-KIT 4. Photos: Constanze Windberg.
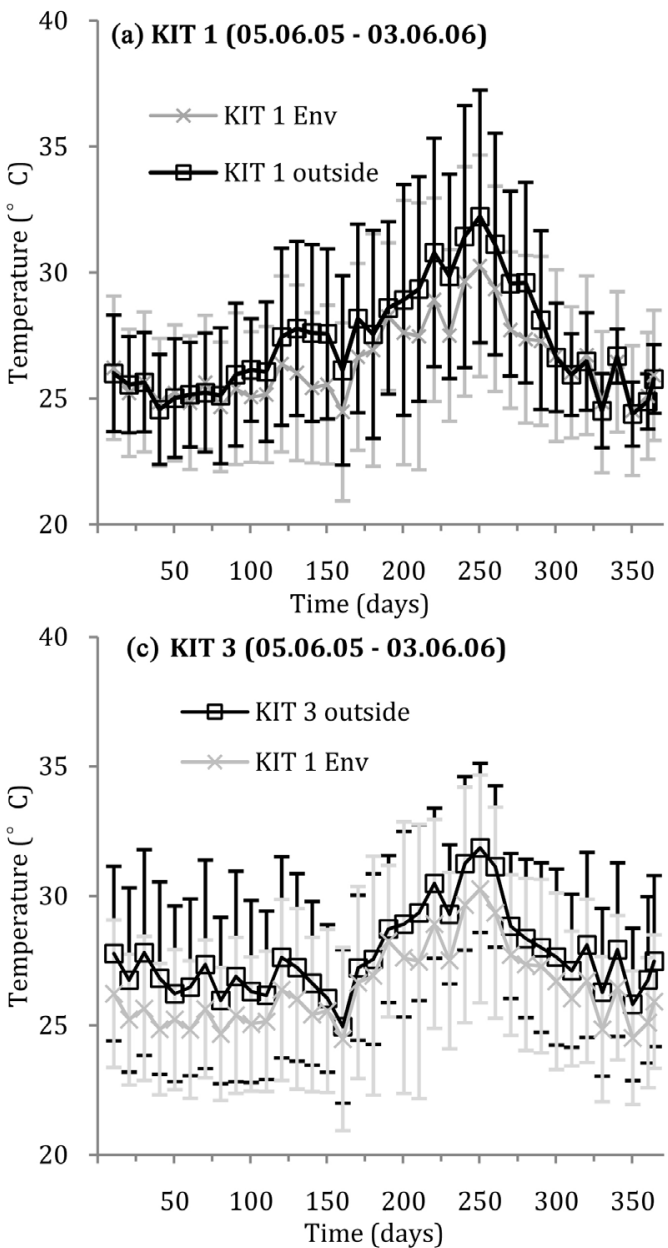

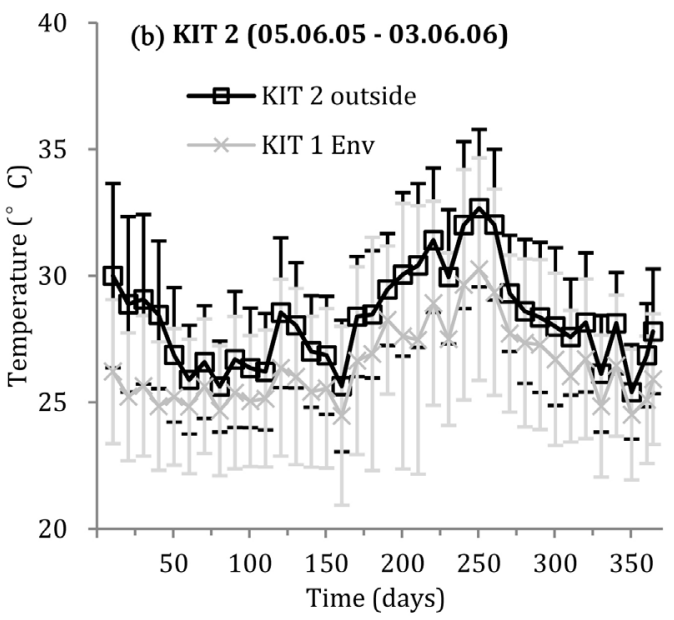

40 ] (d) KIT 4 (05.06.05 - 30.09.05)

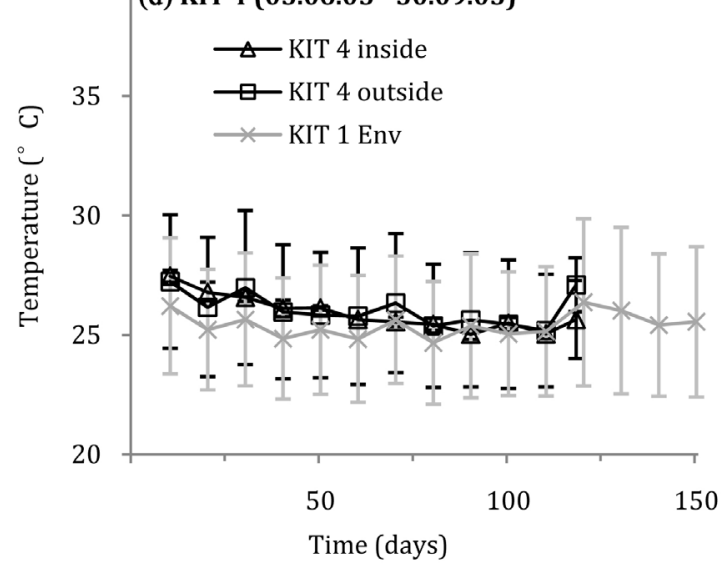

Figure 11. Results of temperature measurements inside the vaults and in the environment in Kitgum, sites KIT 1-KIT 4. 
The study period of KIT1, 2, and 3 is 05.06 .2005 to 03.06 .2006 , 364 days. The study period for KIT 4 is only 118 days. The temperature trends of all four sites are the same. With only KIT 2 having higher temperatures than the other sites in the first 50 days. For all sites the graphs of the temperature outside the heap is above the graph for the environment temperature. The temperature inside and outside the heap at KIT 4 is very similar. Table 5 illustrates minimum and maximum temperature measurements for KIT 1-4 and the environment.

Table 5. Minimum and maximum temperatures inside and outside the heap for KIT 1-4 and the environment at KIT 1.

\begin{tabular}{|c|c|c|c|c|}
\hline \multirow{2}{*}{ Site } & \multicolumn{2}{|c|}{ Temperature inside heap in ${ }^{\circ} \mathrm{C}$} & \multicolumn{2}{|c|}{ Temperature outside heap in ${ }^{\circ} \mathrm{C}$} \\
\hline & Min & Max & Min & Max \\
\hline KIT 1 & - & - & 20.15 & 40.13 \\
\hline KIT 2 & - & - & 21.18 & 38.65 \\
\hline KIT 3 & - & - & 21.11 & 35.60 \\
\hline KIT 4 & 24.65 & 32.64 & 21.10 & 33.10 \\
\hline Environment KIT 1 & \multicolumn{2}{|c|}{ Min } & \multicolumn{2}{|c|}{ Max } \\
\hline Period of 364 days (KIT 1-3) & \multicolumn{2}{|c|}{17.66} & \multicolumn{2}{|c|}{36.16} \\
\hline Period of 118 days (KIT 4) & \multicolumn{2}{|c|}{20.17} & \multicolumn{2}{|c|}{31.67} \\
\hline
\end{tabular}

It can be seen from Figure 11 and Table 5 that all minimum temperatures outside the heap at the sites are considerably above the minimum temperature of the environment. The difference for KIT 1 to KIT 3 ranges from $2.49^{\circ} \mathrm{C}$ to $3.52^{\circ} \mathrm{C}$. The minimum temperature outside the heap at KIT 4 is $0.93^{\circ} \mathrm{C}$ above the minimum environment temperature. At three sites the maximum temperatures outside the heap are above the maximum temperature of the environment. The temperature difference ranges between $1.43^{\circ} \mathrm{C}$ and $3.97^{\circ} \mathrm{C}$. At KIT 3 the maximum temperature outside the vault is $0.56^{\circ} \mathrm{C}$ below the maximum environment temperature. At KIT 4 , the only site with a temperature logger inside the heap, minimum and maximum temperatures inside the heap are above the respective environment temperatures. The average temperature inside the heap is above the average environment temperature. At all sites the average temperature outside the heap is slightly higher, between $0.71^{\circ} \mathrm{C}$ and $1.87^{\circ} \mathrm{C}$, than the average environment temperature. Table 6 shows the average temperatures of inside and outside the heap and the environment and indicates the trend lower or higher temperature than the environment temperature with respective arrows.

Table 6. Average temperatures inside and outside the heap of KIT 1-4 and average temperature in environment KIT 1.

\begin{tabular}{rrrrrr}
\hline \multirow{2}{*}{ Site } & \multicolumn{3}{c}{ Average Temperature in ${ }^{\circ} \mathbf{C}$} & \\
\cline { 2 - 6 } & & Inside heap & Environment & Outside heap \\
\hline KIT 1 & - & - & 26.41 & 27.25 & $\uparrow$ \\
KIT 2 & - & - & 26.41 & 28.28 & $\uparrow$ \\
KIT 3 & - & - & 26.41 & 27.71 & $\uparrow$ \\
KIT 4 & $\uparrow$ & 25.91 & 25.35 & 26.06 & $\uparrow$ \\
\hline
\end{tabular}

$\uparrow:$ Temperature higher than environment. $\downarrow$ : Temperature lower than environment.

\subsubsection{Kampala}

Kampala, the capital of Uganda, is located in the South Central part of Uganda close to the shores of Lake Victoria in the climatic region of tropical rainforest. The annual average temperature ranges between $20.6^{\circ} \mathrm{C}$ and $22.7^{\circ} \mathrm{C}$ and the annual average rainfall amounts to $1291 \mathrm{~mm}$ (see Table 1 ). The average annual relative humidity is $74.5 \%$ [20]. Of the four evaluated UDDTs three are non solar single vault UDDTs. KAMP 2 is a double vault solar UDDT (see Figure 12). 


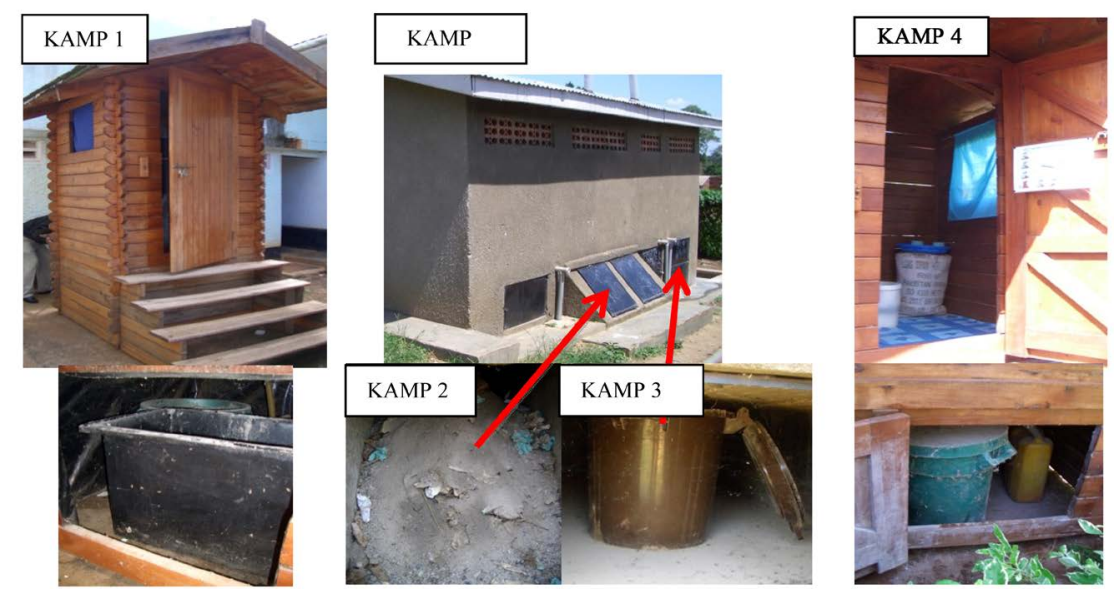

Figure 12. Project sites for evaluation of temperature inside the vault in Kampala, KAB 1-KAB 4. Photos: Constanze Windberg.

In total 14 data loggers were placed in 6 toilets and in the environment. Five of which went missing. Therefore two sites could not be evaluated at all. At KAMP 1 and KAMP 3 the temperature loggers outside the heap got lost, therefore it was not possible to compare the temperature inside the heap with the temperature outside the heap. The temperature logger placed in the environment at KAMP 4 was lost and got replaced after 165 days, therefore it is not possible to compare the temperature inside the vault with the environment for the first 164 days. The results of the readings of the temperature loggers placed in Kampala are shown in Figure 13.
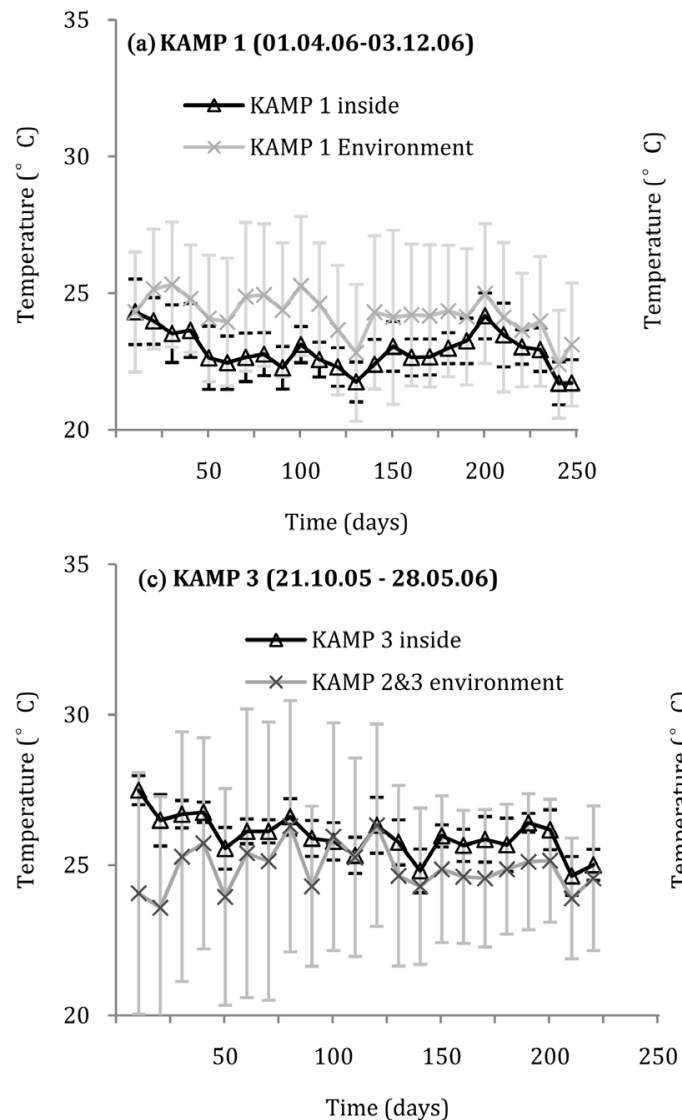
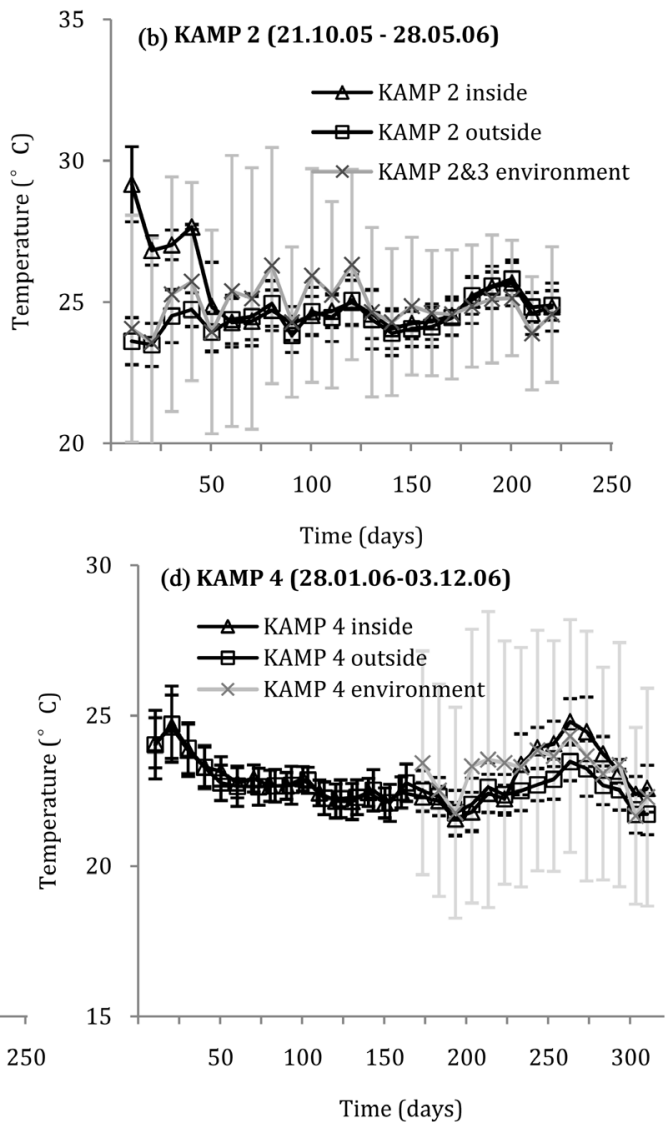

Figure 13. Results of temperature measurements inside the vaults and in the environment in Kampala, sites KAB 1-KAB 4. 
KAMP 1 was evaluated for 247 days, from 01.04 .06 to 03.12 .06 , and KAMP 4 for 310 days from 28.01.06 to 03.12.06. The measurements at KAMP 2\&3 were taken over a period of 220 days, from 21.10.05 to 28.05.06.

The temperature inside the heap of KAMP 1 is lower than the temperature of the environment. For KAMP 2 the temperature in the vault, inside and outside the heap is under or the same as in the environment except for the first 50 days where the temperature inside the heap exceeds the environment temperature and the temperature outside the heap. At KAMP 3 the graph of the temperature inside the vault is above the environment temperature. For KAMP 4 the temperatures inside the vault and in the environment can only be compared after day 165, when the temperature logger in the environment was replaced. The graph of the temperature inside and outside the heap is under the environment temperature until day 240. Then the temperature inside the heap rises slightly above the environment temperature. Until day 225 the inside and outside temperatures are similar. In order to judge the temperature differences Table 7 compares maximum and minimum temperature measurements for the sites KAMP 1 to KAMP 4. Whereas Table 8 compares the mean temperatures and indicates trends for the temperatures inside and outside the heap to be below or above the environment temperature.

Table 7. Minimum and maximum temperatures of inside and outside the heap for KAMP 1-4 and of the respective environment temperatures.

\begin{tabular}{|c|c|c|c|c|}
\hline \multirow{2}{*}{ Site } & \multicolumn{2}{|c|}{ Temperature inside heap in ${ }^{\circ} \mathrm{C}$} & \multicolumn{2}{|c|}{ Temperature outside heap in ${ }^{\circ} \mathrm{C}$} \\
\hline & Min & Max & Min & Max \\
\hline KAMP 1 & 19.66 & 26.66 & - & - \\
\hline \multirow{2}{*}{ Environment KAMP 1} & \multicolumn{2}{|c|}{ Min } & \multicolumn{2}{|c|}{ Max } \\
\hline & \multicolumn{2}{|c|}{18.16} & \multicolumn{2}{|c|}{30.16} \\
\hline KAMP 2 & 22.17 & 31.67 & 21.67 & 27.17 \\
\hline KAMP 3 & 23.69 & 28.19 & - & - \\
\hline \multirow{2}{*}{$\begin{array}{c}\text { Environment KAMP } \\
2 \& 3\end{array}$} & \multicolumn{2}{|c|}{ Min } & \multicolumn{2}{|c|}{ Max } \\
\hline & \multicolumn{2}{|c|}{18.17} & \multicolumn{2}{|c|}{32.67} \\
\hline KAMP $4^{*}$ & 20.65 & 26.15 & 20.10 & 24.60 \\
\hline \multirow{2}{*}{ Environment KAMP 4} & \multicolumn{2}{|c|}{ Min } & \multicolumn{2}{|c|}{ Max } \\
\hline & \multicolumn{2}{|c|}{17.17} & \multicolumn{2}{|c|}{32.67} \\
\hline
\end{tabular}

*Only data from 11.07 .06 onwards considered.

Table 8. Average temperatures inside and outside the heap of KAMP 1-4 and respective average environment temperature.

\begin{tabular}{cccccc}
\hline \multirow{2}{*}{ Site } & \multicolumn{5}{c}{ Average Temperature in ${ }^{\circ} \mathbf{C}$} \\
\cline { 2 - 6 } & \multicolumn{3}{c}{ Inside heap } & Environment & Outside heap \\
KAMP 1 & $\downarrow$ & 22.88 & 24.23 & - & $=/ \downarrow$ \\
KAMP 2 & $=/ \uparrow$ & 25.21 & 24.90 & 24.51 & - \\
KAMP 3 & $\uparrow$ & 25.96 & 24.90 & - & $=/ \downarrow$ \\
KAMP 4 & $=/ \downarrow$ & 23.01 & 23.16 & 22.49 & \\
\hline
\end{tabular}

$\uparrow$ : Temperature higher than environment. $\downarrow$ : Temperature lower than environment. * Only data from 11.07.06 onwards considered.

It can be seen that the minimum temperatures inside the vault (inside and outside the heap) are higher than the minimum environment temperatures. The temperature difference ranges between $1^{\circ} \mathrm{C}$ and $5.52^{\circ} \mathrm{C}$. However, the maximum temperatures inside the vault never exceed the maximum temperatures of the environment, with maximum temperatures being between $1^{\circ} \mathrm{C}$ to $8.07^{\circ} \mathrm{C}$ lower inside the vaults than in the environment. Comparing the mean temperatures (see Table 8) shows that only the temperatures inside the heap of KAMP 2\&3 are slightly above the environment temperatures, $0.31^{\circ} \mathrm{C}$ and $1.06^{\circ} \mathrm{C}$ respectively. And even though KAMP 2 is a solar UDDT the mean temperature inside the heap is $0.75^{\circ} \mathrm{C}$ below the temperature inside the heap of KAMP 3 which is a non-solar single vault UDDT. At KAMP 1 and KAMP 4 the average temperature inside the heap is $1.35^{\circ} \mathrm{C}$ and $0.15^{\circ} \mathrm{C}$ below the average environment temperature respectively. At KAMP 2 and KAMP 4, the only UDDTs with evaluated temperature loggers outside the heap, the average temperature outside the heap is $0.39^{\circ} \mathrm{C}$ and $0.67^{\circ} \mathrm{C}$ respectively below the average environment temperature. 


\subsubsection{Nagalama}

Nagalama is a town in Uganda's central region. It is located approximately $38 \mathrm{~km}$ by road northeast of Kampala. The study site is situated in the compound of St. Francis Hospital, Nagalama. Like Kampala the climatic region is also tropical rainforest. The annual average temperature ranges between $20.6^{\circ} \mathrm{C}$ and $22.4^{\circ} \mathrm{C}$ and the annual average rainfall amounts to $1342 \mathrm{~mm}$ (see Table 1). All eight evaluated UDDTs are single vault solar systems with woven baskets as containers (see Figure 14).
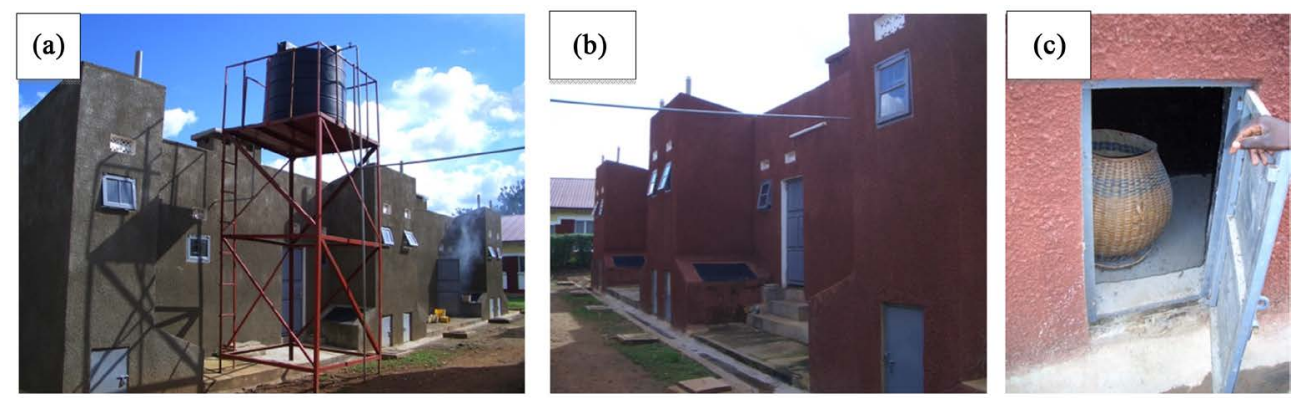

Figure 14. Project sites for evaluation of temperature inside the vault in Nagalama, NAG 1-NAG 8. (a) Block 1 with NAG 4 , 5, 6, 8; (b) Block 2 with NAG 1, 2, 3, 7; (c) Basket inside the vault. Photos: Constanze Windberg.

Sixteen temperature loggers were placed in the vaults of eight UDDTs and two temperature loggers in the environment. Unfortunately both temperature loggers placed in the environment got lost. Therefore the Nagalama sites cannot be fully evaluated. The reason for still including the site in this study lies in an observed phenomenon. Figure 15 depicts the location of each single study UDDT. Figure 16 illustrates the results of the readings of the temperature loggers placed in NAG 1 to 8 .

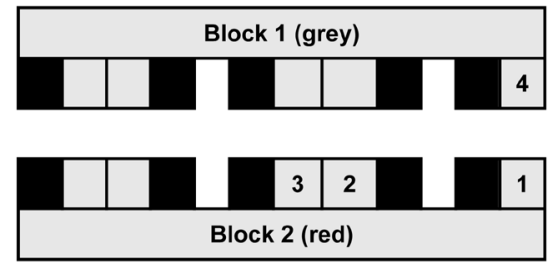

(a)

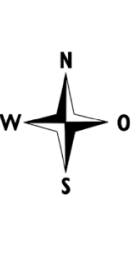

Figure 15. Location of study UDDTs NAG 1 to NAG 8. (a) Study period 08.10.2005 to 02.05.2006; (b) Study period

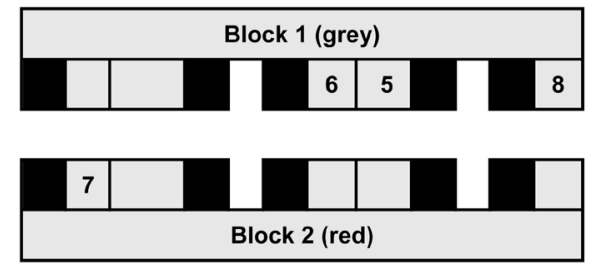

(b) 02.04.2006 to 03.12.2006.
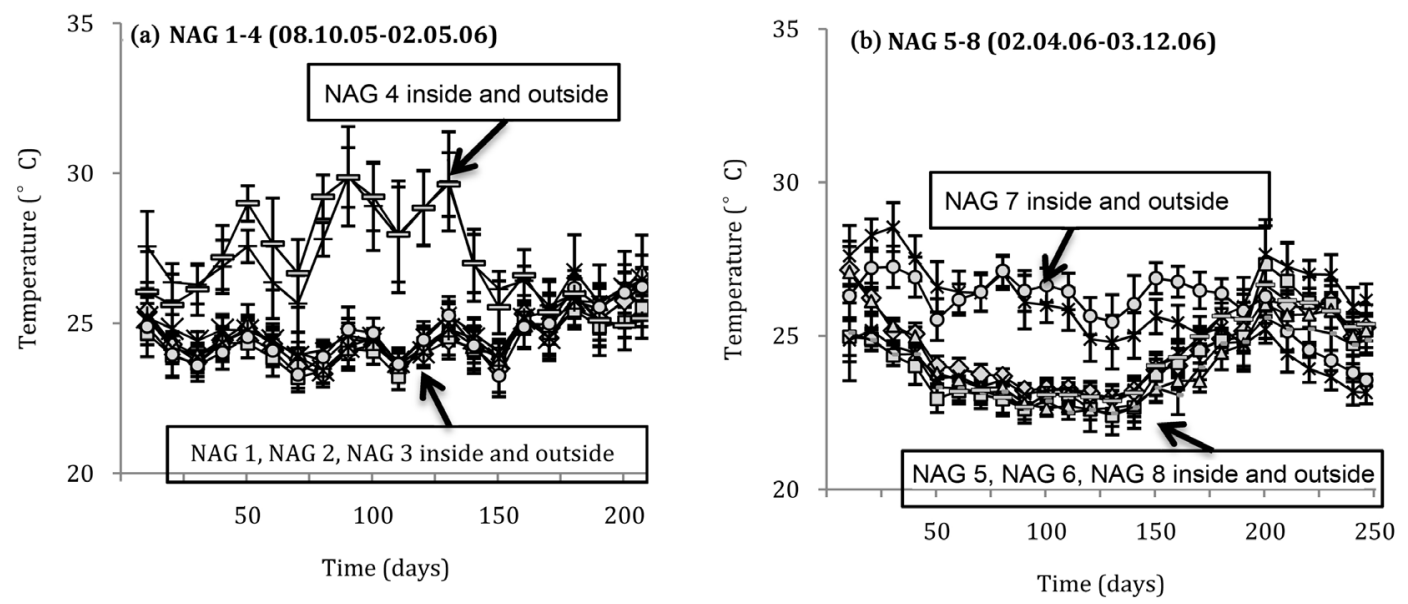

Figure 16. Results of temperature measurements inside the vaults in Nagalama, NAG 1 to NAG 8. (a) Study period 1: 08.10.05-02.05.06. (b) Study period 2: 02.04.06-03.12.06. 
NAG 1 to NAG 4 were evaluated for 207 days, from 08.10.2005 to 02.05.2006, and NAG 5 to NAG 8 for 246 days from 02.04.2006 to 03.12.2006. The two temperature loggers placed in the environment were missing at the time of evaluation. Therefore the temperature inside the vaults of the UDDTs could not be compared with the temperature in the environment and no conclusion could be drawn regarding the heating capacity of the solar panels.

NAG 4 and NAG 8 is the same UDDT but evaluated over different periods (see above). In the first evaluation period three UDDTs were placed at Block 2 and NAG 4/8 was the only study UDDT placed at Block 1, whereas for the second evaluation period three UDDTs, including NAG 4/8, were placed at Block 1 , and only one UDDT was placed at Block 2. NAG 4/8 exceeds the temperature of the other study UDDTs significantly only during the first study period; 08.10.2005 to 02.05.2006, when it is the only observed UDDT at Block 1. During the second study period, from 02.04.06 to 03.12.06, the measurements of NAG 4/8 are similar to the measurements of the other two evaluated UDDTs of Block 1, NAG 5 and NAG 6. Only NAG 7 placed at Block 2 exceeds the temperatures of the other study toilets considerably (see Figure 16). The Ascaris die-off rates also seem to reflect this temperature difference [21]. Figure 16 also shows that for both study periods the temperature graphs of the UDDT placed on the opposite blocks as the rest of the study UDDTs are considerably different for about 170 days and then become similar. It would be interesting to know if the trend would reverse for the other half of the year as Figure 16(b) would suggest. Figure 16(b) shows the graphs of study period 2, which was 39 days longer than study period 1 . The graph already indicates a reverse of trends in the beginning and the end of the study period. Table 9 below quantifies the trends shown in Figure 16 and provides the average temperatures inside and outside the heap as well as the maximum and minimum temperatures measured at each site.

Table 9. Average temperatures inside and outside the heap as well as the maximum and minimum temperatures for NAG 1 to NAG 8.

\begin{tabular}{|c|c|c|c|c|c|c|}
\hline \multirow{2}{*}{ Site } & \multicolumn{3}{|c|}{ Temperature inside heap in ${ }^{\circ} \mathrm{C}$} & \multicolumn{3}{|c|}{ Temperature outside heap in ${ }^{\circ} \mathrm{C}$} \\
\hline & Min & Max & Average & Min & Max & Average \\
\hline \multicolumn{7}{|c|}{ Study period 1:08.10.2005 to 02.05.2006 } \\
\hline NAG 1 & 21.66 & 28.16 & 24.46 & 22.17 & 27.67 & 24.29 \\
\hline NAG 2 & 22.66 & 29.16 & 24.67 & 22.64 & 29.14 & 24.81 \\
\hline NAG 3 & 22.72 & 27.22 & 24.68 & 21.66 & 26.66 & 24.57 \\
\hline NAG $4^{*}$ & 23.15 & 32.65 & 26.97 & 23.67 & 32.16 & 27.11 \\
\hline \multicolumn{7}{|c|}{ Study period 2:02.04.2006 to 03.12 .2006} \\
\hline NAG 5 & 22.17 & 28.66 & 24.59 & 21.17 & 29.17 & 24.20 \\
\hline NAG 6 & 22.15 & 29.15 & 24.24 & 22.14 & 29.14 & 24.70 \\
\hline NAG 7 & 22.18 & 30.18 & 25.67 & 23.15 & 29.15 & 26.02 \\
\hline NAG $8^{*}$ & 20.14 & 30.14 & 23.91 & 21.13 & 27.63 & 24.38 \\
\hline
\end{tabular}

*NAG 4 and NAG 8 being the same UDDT but observed over different time periods. The highlighted sites, NAG 4 and NAG 7, being located on the opposite block than the rest of the study UDDTs.

It can be seen in Table 9 that for both study periods the average temperatures inside and outside the heap of the UDDTs placed on the opposite block to the rest of the study UDDTs are higher. For study period 1 average temperatures inside the UDDT vaults are similar for Block 2, NAG 1-3, and only vary between $0.01^{\circ} \mathrm{C}$ and $0.52^{\circ} \mathrm{C}$ from each other. But do vary between the different blocks, NAG 4 and NAG 1-3, between $2.29^{\circ} \mathrm{C}$ and $2.82^{\circ} \mathrm{C}$. This trend is not so significant for study period 2 since the values are already including the reverse of the trend. For study period 2 the difference of average temperatures inside the vault of the three UDDTs placed at Block 1 ranges between $0.18^{\circ} \mathrm{C}$ and $0.68^{\circ} \mathrm{C}$, whereas the difference of average temperature inside the vaults of UDDTs at Block 1 to NAG 7 at Block 2 ranges between $1.08^{\circ} \mathrm{C}$ and $1.82^{\circ} \mathrm{C}$. This could be explained with different shading patterns over the course of a year and strengthens once again how important the positioning of the UDDTs is. A more evenly distributed position of the different study UDDTs could offer clarification. For all sites, NAG 1-8, the average temperature inside the heap is similar to the average temperature outside the heap, the temperature differences only ranging between $0.11^{\circ} \mathrm{C}$ and $0.48^{\circ} \mathrm{C}$. 


\subsubsection{Rwenshama}

Rwenshama is located in the Western Region of Uganda on the shores of Lake Edward. The distance from Rwenshama to Kampala is approximately $323 \mathrm{~km}$ (as the crow flies). The climatic region of Rwenshama is tropical wet and dry savannah climate. The annual average temperature ranges between $22.9^{\circ} \mathrm{C}$ and $23.8^{\circ} \mathrm{C}$ and the annual average rainfall amounts to $942 \mathrm{~mm}$ (see Table 1). All five evaluated UDDTs are double vault solar systems. Figure 17 shows examples of evaluated UDDTs.
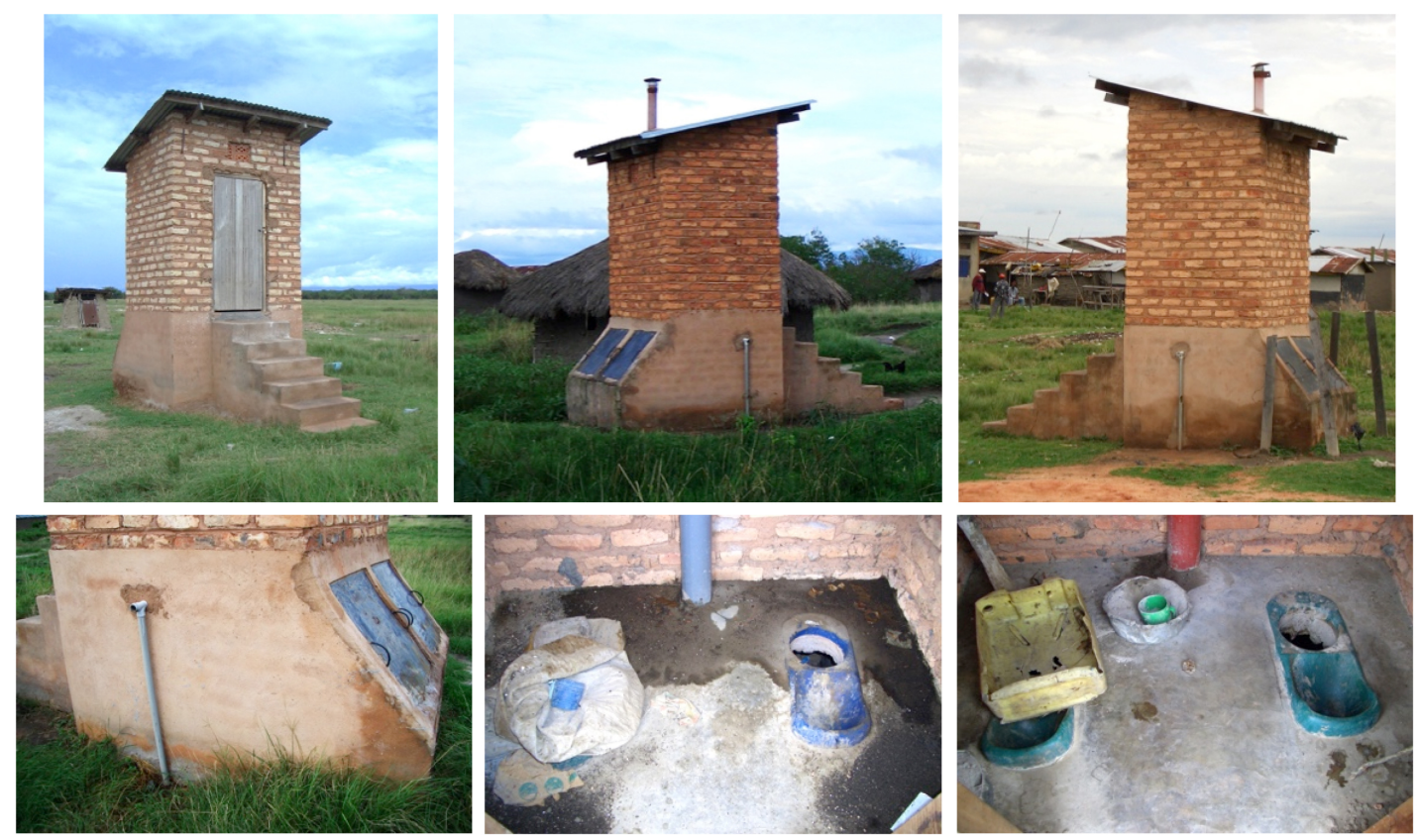

Figure 17. Examples of evaluated UDDTs in Rwenshama. Photos: Constanze Windberg.

In general UDDTs in Rwenshama had several problems including misuse, corrosion of iron sheets, weak mortar, insects, flooding and therefore water intrusion. Fourteen data loggers were placed inside the vaults of seven UDDTs and one data logger was placed in the environment. Unfortunately five data loggers were lost. Therefore only five UDDTs could be evaluated. Figure 18 shows the location of the seven study UDDTs in Rwenshama. Originally three UDDTS were oriented to West, two to East and two to North. Now that two UDDTs, RWN 6 and RWN 7, could not be evaluated anymore, only one evaluated UDDT is facing North and one is facing East. Three UDDTs are facing West. Figure 19 illustrates the readings of the temperature loggers of the five evaluated UDDTs.

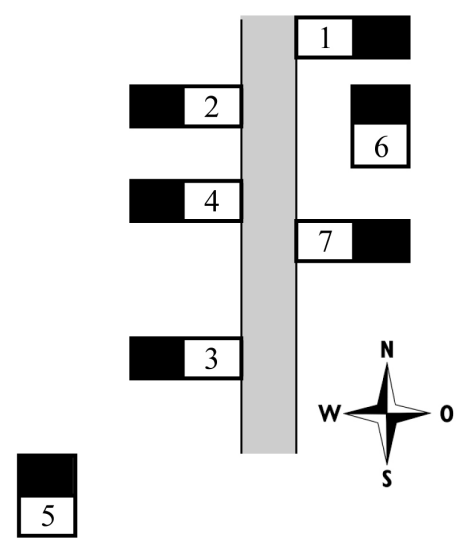

Figure 18. Location of study UDDTs Rwenshama. 

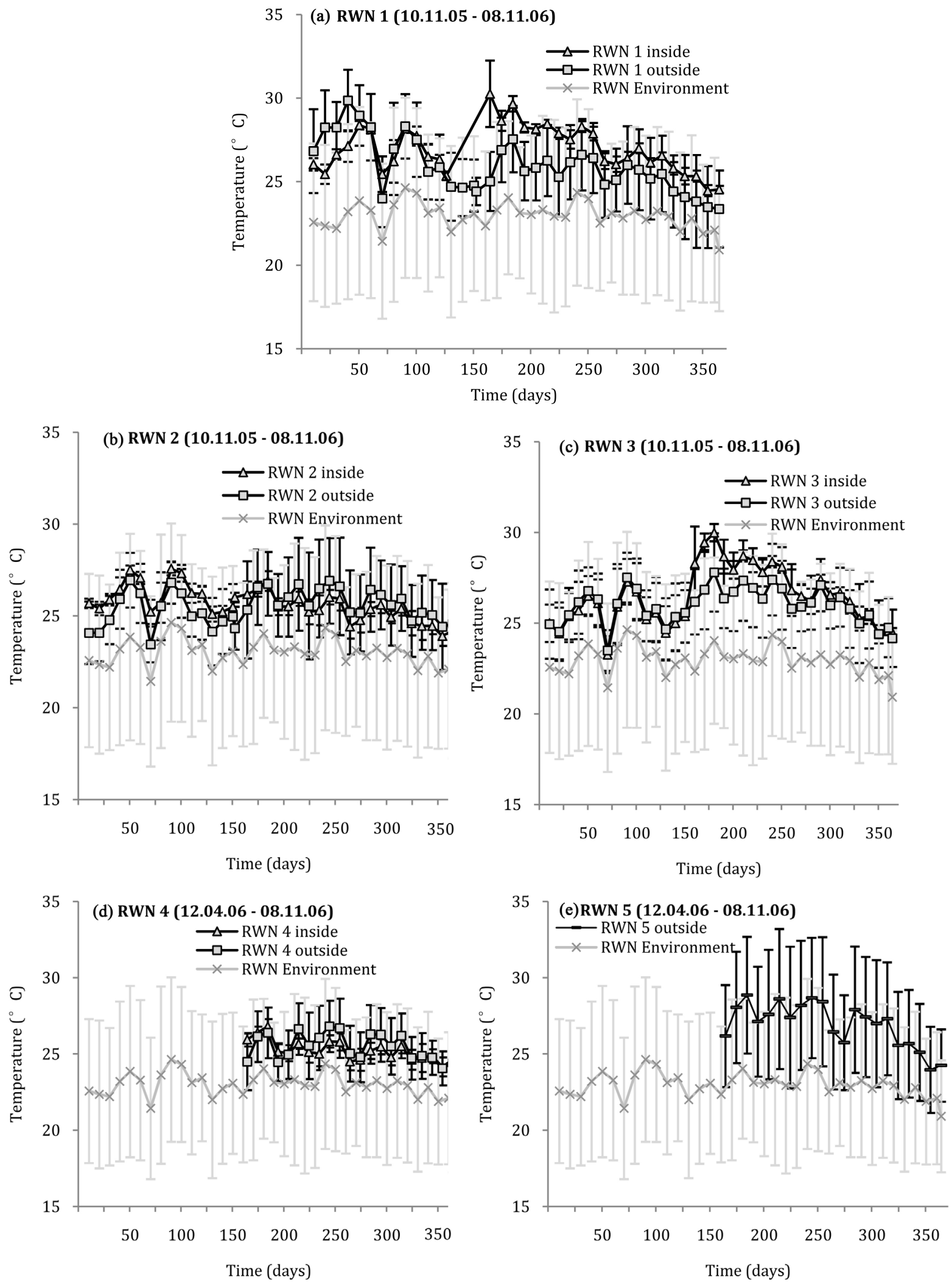

Figure 19. Results of temperature measurements inside the vaults and in the environment in Rwenshama, sites RWN 1 to RWN 5. 
RWN 4 and RWN 5 were only studied for a period of 150 days, from 12.04.2006 to 08.11.2006, whereas the other UDDTs were studied for 364 days, from 10.11.2005 to 08.11.2006. In RWN 5 the temperature logger placed inside the heap got lost, therefore only the temperature outside the heap is illustrated in Figure 19 above. The temperature recorded by the logger placed outside the heap of RWN 5 seems relatively high with a high standard derivation. The measurements suggest that this logger was placed too near to the black iron sheet covering the vault. Since the temperature logger inside the heap could not be found at the day of sampling the outside measurement cannot be evaluated against the measurements inside the heap.

The graphs of the temperatures inside and outside the heap of all study UDDTs are above the environment temperature. At RWN 1 and RWN 3 the temperature inside the heap is above or similar to the temperature inside the heap, whereas at RWN 2 the graph of the temperature outside the heap is slightly below the inside temperature for approximately the first half of the measurement period. For the second half, the outside temperature is slightly above the inside temperature. At RWN 4 the temperature inside and outside the heap is very similar with the outside temperature slightly exceeding the inside temperature from time to time. In order to judge the temperature differences Table 10 compares maximum and minimum temperature measurements for the sites RWN 1 to RWN 5.

Table 10. Minimum and maximum temperatures of inside and outside the heap for RWN 1-5 and of the respective environment temperatures.

\begin{tabular}{|c|c|c|c|c|}
\hline \multirow{2}{*}{ Site } & \multicolumn{2}{|c|}{ Temperature inside heap in ${ }^{\circ} \mathrm{C}$} & \multicolumn{2}{|c|}{ Temperature outside heap in ${ }^{\circ} \mathrm{C}$} \\
\hline & Min & Max & Min & Max \\
\hline RWN 1 & 24.15 & 34.14 & 19.11 & 33.16 \\
\hline RWN 2 & 22.67 & 28.17 & 19.16 & 31.16 \\
\hline RWN 3 & 21.61 & 30.65 & 21.15 & 31.16 \\
\hline Environment & \multicolumn{2}{|c|}{ Min } & \multicolumn{2}{|c|}{ Max } \\
\hline 10.11.05-08.11.06 & \multicolumn{2}{|c|}{14.16} & \multicolumn{2}{|c|}{36.66} \\
\hline RWN 4 & 22.61 & 27.61 & 20.15 & 29.65 \\
\hline RWN 5 & - & - & 19.16 & 35.65 \\
\hline Environment & \multicolumn{2}{|c|}{ Min } & \multicolumn{2}{|c|}{ Max } \\
\hline 12.04.06-08.11.06 & \multicolumn{2}{|c|}{14.16} & \multicolumn{2}{|c|}{36.66} \\
\hline
\end{tabular}

Table 10 shows that the minimum temperatures inside the heap are between $0.46^{\circ} \mathrm{C}$ and $5.04^{\circ} \mathrm{C}$ above the minimum temperatures outside the heap. Except for RWN 1 the maximum temperatures inside the heap are below the maximum temperatures outside the heap (between $0.51^{\circ} \mathrm{C}$ and $2.99^{\circ} \mathrm{C}$ ). In $\mathrm{RWN} 1$ the maximum temperature inside the heap is $0.98^{\circ} \mathrm{C}$ above the temperature outside the heap. In none of the UDDTs the temperature rises above the maximum measured environment temperature. However, the minimum temperatures inside the heap are considerably above the minimum environment temperatures, between $8.43^{\circ} \mathrm{C}$ and $9.99^{\circ} \mathrm{C}$. Table 11 compares the mean temperatures and indicates trends for the temperatures inside and outside the heap to be below or above the environment temperature.

Table 11. Average temperatures inside and outside the heap of KAMP 1-4 and respective average environment temperature.

\begin{tabular}{lccccc}
\hline \multirow{2}{*}{ Site } & \multicolumn{3}{c}{ Average Temperature in ${ }^{\circ} \mathbf{C}$} \\
\cline { 2 - 6 } & \multicolumn{2}{c}{ Inside heap } & Environment & \multicolumn{2}{c}{ Outside heap } \\
\hline RWN 1 & $\uparrow$ & 26.98 & 23.00 & 25.98 & $\uparrow$ \\
RWN 2 & $\uparrow$ & 25.65 & 23.00 & 25.52 & $\uparrow$ \\
RWN 3 & $\uparrow$ & 26.46 & 23.00 & 26.00 & $\uparrow$ \\
RWN 4 & $\uparrow$ & 25.24 & $22.97^{*}$ & 25.48 & $\uparrow$ \\
RWN 5 & - & - & $22.97^{*}$ & 26.93 & $\uparrow$ \\
\hline
\end{tabular}

$\uparrow$ : Temperature higher than environment. $\downarrow$ : Temperature lower than environment. ${ }^{*}$ Only data from 12.04.2006 onward considered. 
In all study UDDTs in Rwenshama the average temperatures inside and outside the heap are above the average environment temperature (see Table 11). The temperature difference between the temperature inside the heap and the environment ranges between $2.27^{\circ} \mathrm{C}$ and $3.98^{\circ} \mathrm{C}$ and the difference between the average temperature outside the heap and the environment between $2.51^{\circ} \mathrm{C}$ and $3.96^{\circ} \mathrm{C}$. The average temperature inside the heap for RWN 1-3 is higher than the average temperature outside the heap $\left(0.13^{\circ} \mathrm{C}-1^{\circ} \mathrm{C}\right)$. For RWN 4 the average temperature inside the heap is $0.25^{\circ} \mathrm{C}$ below the average temperature outside the heap.

\subsubsection{Comparison of All Sites}

After evaluating every site separately, this chapter compares the findings of the different sites to inform general conclusions and recommendations. Of 28 evaluated UDDTs four were non-solar UDDTs (see Table 2). The temperature inside the vault of only 18 UDDTs could be directly compared to the environment temperature because of missing temperature loggers. 11 evaluated UDDTs had temperature loggers inside and outside the heap at the time of sampling. At the remaining seven UDDTs either the temperature logger outside or inside was missing. Table 12 gives an overview of the relation between the temperatures inside the vault (inside and outside the heap) and the environment temperature at every chosen geographical location.

Table 12. Relation between the temperatures inside the vault and the environment temperature at all sites.

\begin{tabular}{|c|c|c|c|c|c|c|c|c|}
\hline \multirow{3}{*}{$\begin{array}{l}\text { Site/climatic } \\
\text { region }\end{array}$} & \multicolumn{4}{|c|}{$\Delta$ Temp 1 = inside Temp-environment Temp } & \multicolumn{4}{|c|}{$\Delta$ Temp $2=$ outside Temp-environment Temp } \\
\hline & \multicolumn{2}{|c|}{ Inside Temp higher } & \multicolumn{2}{|c|}{ Environment Temp higher } & \multicolumn{2}{|c|}{ Outside Temp higher } & \multicolumn{2}{|c|}{ Environment Temp higher } \\
\hline & $\begin{array}{l}\text { No of } \\
\text { UDDTs }\end{array}$ & $\begin{array}{c}\text { Variation } \\
\text { of } \Delta \text { Temp } \\
1 \text { in }{ }^{\circ} \mathrm{C}\end{array}$ & $\begin{array}{l}\text { No of } \\
\text { UDDTs }\end{array}$ & $\begin{array}{c}\text { Variation } \\
\text { of } \Delta \text { Temp } 1 \\
\text { in }{ }^{\circ} \mathrm{C}\end{array}$ & $\begin{array}{l}\text { No of } \\
\text { UDDTs }\end{array}$ & $\begin{array}{l}\text { Variation of } \\
\Delta \text { Temp } 2 \text { in } \\
{ }^{\circ} \mathrm{C}\end{array}$ & $\begin{array}{l}\text { No of } \\
\text { UDDTs }\end{array}$ & $\begin{array}{c}\text { Variation } \\
\text { of } \Delta \text { Temp } 2 \\
\text { in }{ }^{\circ} \mathrm{C}\end{array}$ \\
\hline \multicolumn{9}{|l|}{ Highlands } \\
\hline Kabale & 4 & $0.10-1.99$ & 1 & 0.69 & 1 & 1.6 & 3 & $0.43-0.95$ \\
\hline \multicolumn{9}{|l|}{ Rainforest } \\
\hline Kampala & 2 & $0.31-1.06$ & 2 & $0.15-1.35$ & - & - & 2 & $0.39-0.67$ \\
\hline \multicolumn{9}{|l|}{ Savannah } \\
\hline Kitgum & 1 & 0.56 & - & - & 4 & $0.71-1.87$ & - & - \\
\hline Rwenshama & 4 & $2.27-3.98$ & - & - & 5 & $2.51-3.96$ & - & - \\
\hline
\end{tabular}

Even though the 8 non-solar UDDTs evaluated in Nagalama could not be compared to the environment since the respective temperature logger got lost and the 4 evaluated non-solar UDDT systems in Kampala and Kabale did not show a clear trend with the average temperatures inside the vault being above, below and similar to the average environment temperatures general tendencies can be observed.

The evaluation of temperatures inside the vaults of solar and non-solar UDDT systems in Uganda shows that at most sites the average temperatures inside the vaults are above the average temperatures in the environment (see Table 12). Except for the sites in Rwenshama the temperature difference is below $2^{\circ} \mathrm{C}$. In Rwenshama the average temperature inside the vault rises close to $4^{\circ} \mathrm{C}$ above the average environment temperature. Rwenshama together with Kitgum is located in a savannah climatic zone and has the highest annual average temperatures compared to the other sites (see Table 1). All study UDDTs in Rwenshama are double vault solar UDDTs. A separate related study on Ascaris die-off seems to indicate a relation between this higher temperature and a faster Ascaris die-off at Rwenshama sites compared to the other sites [21].

When comparing the temperature values of Rwenshama with the measurements in Kitgum, which is also located in a tropical savannah climate it becomes apparent that in Kitgum the temperatures inside the vault only rise up to $1.87^{\circ} \mathrm{C}$ above the environment temperature. This can mainly be explained by the different climate classification according to Köppen-Geiger (see Table 1). The climate in Kitgum is classified as tropical wet and dry savannah climate Aw. Whereas Rwenshama is located in the tropical wet and dry savannah climate As. Which means the dry season in Rwenshama occurs during the time of higher sun and longer days. However, in most places with tropical wet and dry savannahclimates, such as Kitgum, the dry season occurs during the time of lower sun and shorter days. This difference is believed to also reflect in the lower temperatures inside the 
vaults of the UDDTs in Kitgum. Furthermore, the solar panels used for UDDTs in Kitgum are corrugated iron sheets, which are not completely black (see Figure 10). The UDDTs in Kitgum are also located in a more densely populated area and are not necessarily free standing like the UDDTs in Rwenshama (see Figure 17). The comparison of Kitgum and Rwenshama shows once again that the decision for a solar UDDT has to be carefully assessed.

Of the original ten non-solar study UDDTs only four could be finally evaluated. Two of these non-solar study UDDTs, KAB 3 and KAMP 3, are immediately beside a solar UDDT (see Figure 8 and Figure 12) and therefore allow for a direct comparison. The average temperature inside the heap of $\mathrm{KAB} 3$ is $0.03^{\circ} \mathrm{C}$ below the average temperature inside the heap of the adjacent solar UDDT KAB 2 (see Table 4). The average temperature inside the heap of KAMP 3 is $0.75^{\circ} \mathrm{C}$ above the average temperature inside the heap of the adjacent solar UDDT KAMP 2 (see Table 8). This limited data of the direct comparison and the overall data from the study, showing the low temperature increase experienced at the solar UDDTs (see Table 12), do not confirm a general temperature rise caused by the solar sheets installed at solar UDDTs.

\section{Limitations, Conclusions and Recommendations}

The study concentrated on operational UDDTs. The placement of the loggers and the scheduling of the sampling were therefore dependent on the filling pattern of the specific UDDTs. Only UDDTs with vaults filled at a certain time could be used for the study. Therefore the choice of specific design, location and orientation of the study UDDTs was limited and not balanced. Constructing study sites could have addressed these issues. However, the compromises were considered necessary to draw a more realistic picture.

The main factors limiting this study were lost, misplaced or not recovered data loggers and therefore missing data (see Section 4.2). At some sites the temperature logger recording the temperature of the environment was missing; therefore the temperature inside the vaults could not be compared and a supposed temperature rise not evaluated. Some data loggers also compromised data. These temperature measurements were not usable. Some data loggers were placed in UDDTs located in conflict zones with limited infrastructure. At the planned time of recovery the means to recover these temperature loggers were not available. The existing technologies today, allowing for real time remote data logging, would prevent this problem. Irregularities, loss and failure can be realised without delay and respective measures taken. Far less logistical planning is necessary.

Overall limited resources did not allow for a bigger sample size and only a restricted number of non solar UDDTs were available for the study.

In spite of the limitation described above the presented results allow for general conclusions and recommendations considering that an effective sanitation system should be hygienically safe and as user friendly and cost effective as possible. It was observed that even though solar UDDTs are designed to use the irradiation for heating they are not always located in a place where absorption of solar irradiation would be possible, such as shady places. Furthermore, the study shows that the temperature inside the vaults of solar UDDTs is not necessarily higher than inside the vaults of non-solar UDDTs. With the exception of Rwenshama, even if there is a temperature increase achieved, it is too minimal to justify the higher investment cost and the problems associated with the construction of solar UDDTs (see Section 4.1). The achieved temperatures are not high enough or held long enough to significantly increase the rate of dehydration or to even facilitate any hygienisation effect. However, the significant temperature rise inside the vaults of UDDTs located at Rwenshama shows the importance of the climatic region.

The recommendation based on the results of this study is therefore not to promote the construction of solar UDDTs as a standard solution any longer, but to rather promote non-solar UDDT designs as standard solutions. The decision for solar UDDTs has to be site specific. Before deciding for a solar UDDT the climatic conditions have to be thoroughly assessed. The extra cost of the construction of a solar UDDT has to be justified. The final solar design needs to be optimised with high quality to avoid unnecessary cost and associated problems.

Constructing non-solar UDDTs will give more freedom regarding the location and orientation of the UDDTs. Particularly for urban contexts single vault non-solar UDDT systems combined with a service provider for operation and maintenance are considered to be most appropriate. Also other ecosan technologies, such as Terra Preta Sanitation [22] suitable for the urban context should be explored more. For rural contexts a double vault system is still considered appropriate.

The present study should be also seen in relation to the Ascaris die-off study currently under evaluation [21]. This study will provide a better indication of the impact of minimal temperature variations on Ascaris die-off. 


\section{Acknowledgements}

This study was part of a PhD research project hosted and funded by Hamburg University of Technology TUHH and Rosa-Luxemburg-Foundation. The author would like to acknowledge the Austrian Development Agency, the Directorate of Water Development Kampala, and South Western Towns Water and Sanitation Project (SWTWS) for their generous support.

\section{References}

[1] Windberg, C., Otterpohl, R., Nkurunziza, A. and Nasinyama, G. (2005) The UPA-Ecosan Concept in Uganda: SocioAcceptability and Hygiene Safety. Proceedings of the 31st WEDC International Conference, Kampala, October 2005, 96-99.

[2] GTZ Ecosan Team (2006) Technical Data Sheets for Ecosan Components. 02 Dehydration Toilets. http://betuco.be/compost/Dehydration-toilets\%20ecosan.pdf

[3] Onyango, P. and Odhiambo, O. (2009) Technical Guide to EcoSan Promotion. EU-GTZ/SIDA EcoSan Promotion Project, Ministry of Water \& Irrigation, Nairobi.

[4] WaterAid (2011) Construction of Ecological Sanitation Latrine. Technical Handbook, WaterAid, Nepal.

[5] Eawag, Wafler, M. and Spuhler, D. (2014) UDDT. http://www.sswm.info/

[6] Tilley, E., Luethi, C., Morel, A., Zurbruegg, C. and Schertenleib, R. (2008) Compendium of Sanitation Systems and Technologies. Swiss Federal Institute of Aquatic Science and Technology (EAWAG), Duebendorf.

[7] Gensch, R., Miso, A., Itchon, G. and Sayre, E. (2010) Low-Cost Sustainable Sanitation Solutions for Mindanao and the Philippines-A Practical Construction Field Guide. Sustainable Sanitation Center, Xavier University, Cagayan de Oro City.

[8] Hoffmann, H. (2012) Construction of Bench Style Double Vault Urine Diversion Toilet and Alternatives. Rotaria del Peru SAC, Lima.

[9] Rieck, C., von Münch, E. and Hoffmann, H. (2012) Technology Review of Urine-Diverting Dry Toilets (UDDTs)— Overview on Design, Management, Maintenance and Costs. Deutsche Gesellschaft für Internationale Zusammenarbeit (GIZ) GmbH, Eschborn.

[10] WECF (2015) Urine Diverting Dry Toilets-Principles, Operation and Construction. 2nd Revised Edition. www.sanitation.wecf.eu/

[11] Tilley, E., Ulrich, L., Luethi, C., Reymond, P. and Zurbruegg, C. (2014) Compendium of Sanitation Systems and Technologies. 2nd Revised Edition, Swiss Federal Institute of Aquatic Science and Technology (Eawag), Duebendorf.

[12] Clouet, B. (2010) Easy Shower Latrine Technical Handbook. International Development Enterprises (IDE), Professionnels du Développement Solidaire.

[13] Deegener, S., Samwel, M. and Gabizon, S. (2006) Urine Diversion Toilets-Principles, Operation and Construction. WECF, Utrecht/Munich.

[14] Morgan, P. (2007) Toilets That Make Compost—Low-Cost, Sanitary Toilets that Produce Valuable Compost for Crops in an African Context. SEI/Aquamor, Harare.

[15] Panse, D., et al. (2009) Urine Diversion Dehydration Toilet (UDDT) Construction Manual. Ecosan Services Foundation (ESF), Pune.

[16] Winblad, U. and Simpson-Hébert, M. (2004) Ecological Sanitation—Revised and Enlarged Edition. Stockholm Environment Institute, Stockholm. www.ecosanres.org/pdf_files/Ecological_Sanitation_2004.pdf

[17] Rieck, C. (2010) Case Study of SuSanA Projects. UDDTs Implemented via CBOs and Water Services Trust Fund, Nyanza, Western and Other Provinces. www.susana.org

[18] Wikipedia (2016) Kabale District. http://en.wikipedia.org

[19] Weatherbase (2016) http://www.weatherbase.com

[20] Wikipedia (2016) Kampala. https://en.wikipedia.org/wiki/Kampala

[21] Windberg, C. (2016) Preliminary Research Findings of Ascaris Die-Off Study at 25 Operational UDDT Sites in Uganda. Unpublished.

[22] Windberg, C., Yemaneh, A. and Otterpohl, R. (2013) Terra Preta Sanitation: A New Tool for Sustainable Sanitation in Urban Areas? Proceedings of the 36th WEDC International Conference, Nakuru, 1-5 July 2013. 


\section{Submit or recommend next manuscript to SCIRP and we will provide best service for you:}

Accepting pre-submission inquiries through Email, Facebook, LinkedIn, Twitter, etc.

A wide selection of journals (inclusive of 9 subjects, more than 200 journals)

Providing 24-hour high-quality service

User-friendly online submission system

Fair and swift peer-review system

Efficient typesetting and proofreading procedure

Display of the result of downloads and visits, as well as the number of cited articles

Maximum dissemination of your research work

Submit your manuscript at: http://papersubmission.scirp.org/ 